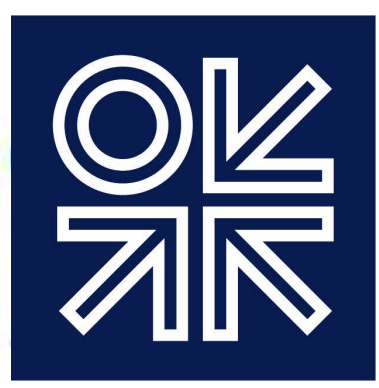

THE OXFORD

INSTITUTE

FOR ENERGY

STUDIES

February 2019

\title{
Narratives for Natural Gas in Decarbonising European Energy Markets
}

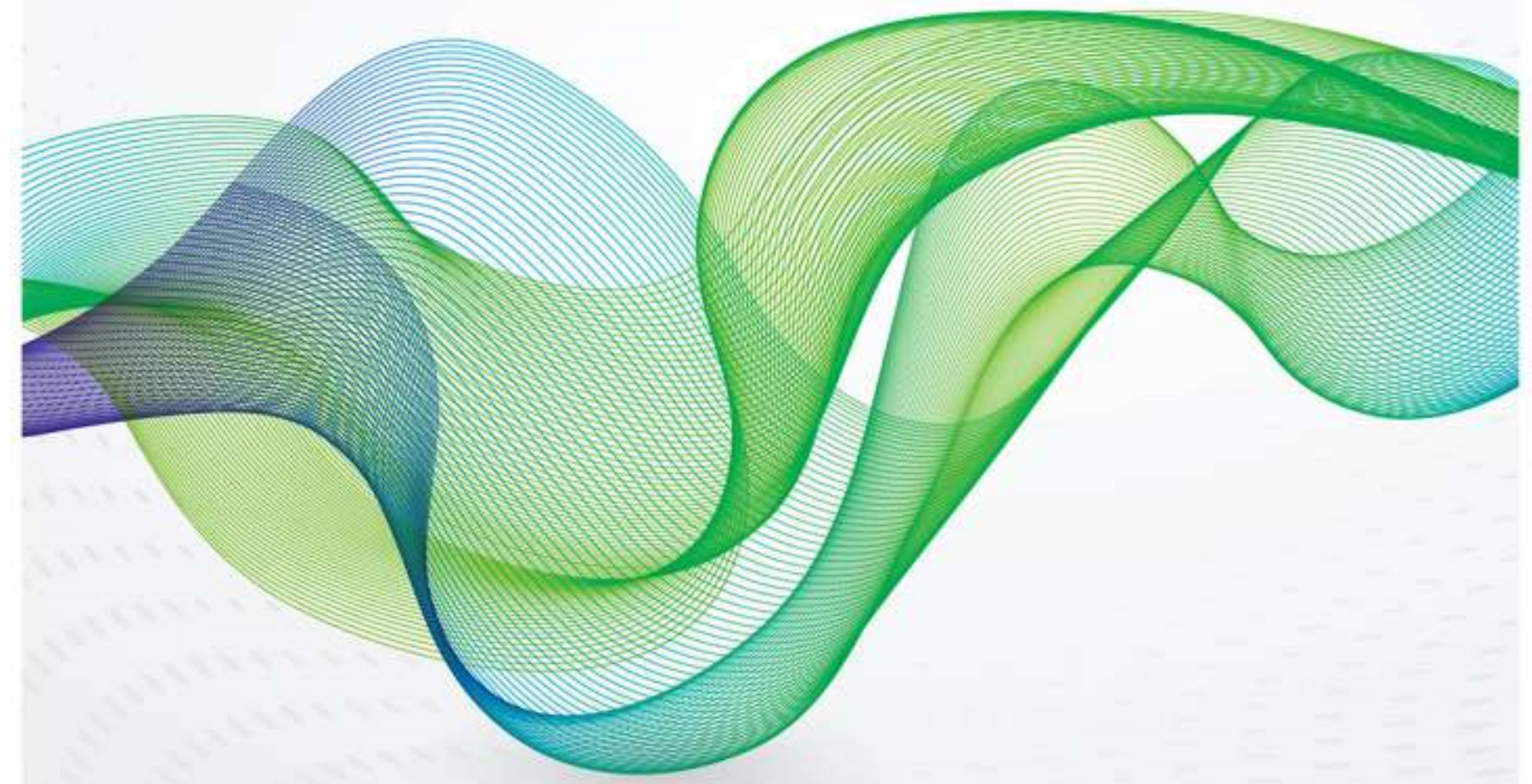


The contents of this paper are the author's sole responsibility. They do not necessarily represent the views of the Oxford Institute for Energy Studies or any of its members.

Copyright @ 2019

Oxford Institute for Energy Studies

(Registered Charity, No. 286084)

This publication may be reproduced in part for educational or non-profit purposes without special permission from the copyright holder, provided acknowledgment of the source is made. No use of this publication may be made for resale or for any other commercial purpose whatsoever without prior permission in writing from the Oxford Institute for Energy Studies.

ISBN: 978-1-78467-128-0

DOI: https://doi.org/10.26889/9781784671280 

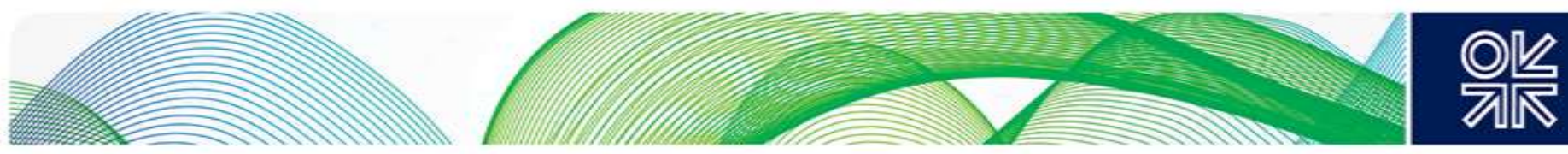

\section{Acknowledgements}

My grateful thanks to colleagues at OIES for their comments and help with data, especially James Henderson and Martin Lambert. I would also like to thank many sponsors of the OIES Gas Programme who provided comments and helpful suggestions during the preparation of this paper. Liz Henderson provided excellent editing suggestions and Kate Teasdale did everything else with her customary efficiency.

I should stress that the views expressed, and any mistakes which remain, are solely my responsibility. 

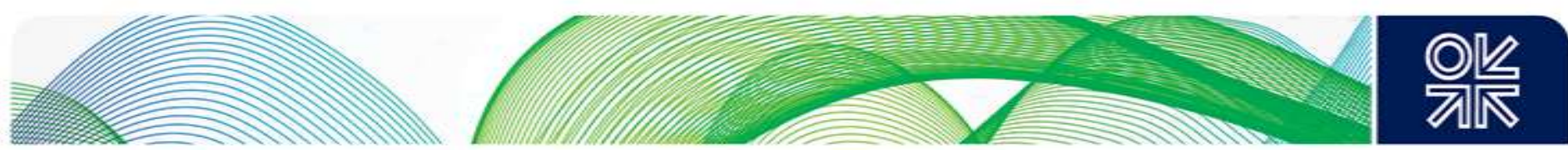

\section{Preface}

Over the past two years Jonathan Stern, the founder of the Gas Programme at OIES and a distinguished research fellow, has been developing a framework to analyse the future of gas in a global energy economy within which decarbonisation and improved environmental standards are becoming key drivers. His first paper, "The Future of Gas in Decarbonising European Energy Markets - the need for a new approach" initially raised the concern that if the gas industry did not take decarbonisation seriously then it risked being significantly marginalised and ultimately removed from the European energy system. His second paper, "Challenges to the Future of Gas: unburnable or unaffordable?" extended the debate to a global scale and argued that, although in a number of regions outside Europe the issue of air quality favours the use of gas (especially over coal), consumption will only reach its full potential if the commodity is priced competitively. Stern posited that delivered prices averaging $\$ 6-8 / \mathrm{mmbtu}$ were the maximum which LNG exporters could expect to receive in order to remain affordable and competitive with alternative sources of energy.

In this third paper, the author returns to the theme of decarbonisation in Europe and asserts that the time has now come for the gas industry to develop narratives for its contribution to the achievement of Europe's carbon reduction targets. A major assumption is that European policy makers will follow through on the commitments they have made since the COP21 agreement was signed in Paris in 2015. Some might be tempted to argue that this is a rather speculative premise on which companies and an industry should build a long-term strategy, especially considering the potential costs involved. However, Stern argues that, although politicians may have a poor track record on fulfilling promises, for the gas industry the risk of assuming that carbon targets will be significantly delayed or abandoned is too high to contemplate. A decarbonised European energy system within which the gas industry has made insufficient effort to reduce its carbon footprint is likely to be an energy system with dramatically lower gas consumption by 2050.

As a result, the industry has a choice. Either accept that gas demand in Europe is going to decline after 2030, and re-focus on other expanding markets (particularly in Asia) or take a positive step towards developing and implementing decarbonisation narratives which will convince European politicians that gas should be taken seriously as a significant part of energy balances post-2030. This will not be easy, as Stern acknowledges that Europe's market liberalisation has fragmented the industry and divided the value chain in a way that leaves many of the players with very different incentives. As a result, not only do companies involved in all parts of the chain need to cooperate more and develop concrete pilot projects to demonstrate that they are developing a decarbonisation strategy, but policy-makers may need to accept that more and very different regulation, compared with what has been introduced over the past three decades, will be needed.

The conclusions of this paper may be regarded as controversial by some readers but, given the importance of the issue to the future of the gas industry in Europe, we believe that they make an important contribution to a debate which we will continue to catalyse at OIES over the coming years.

James Henderson

Director, Natural Gas Programme

Oxford Institute for Energy Studies 


\section{Contents}

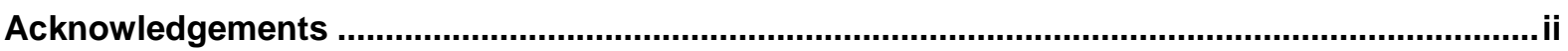

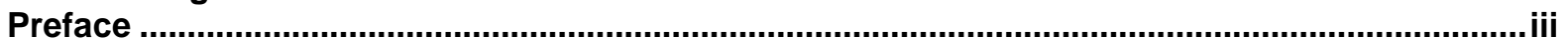

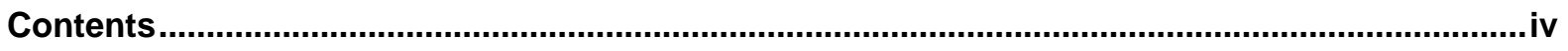

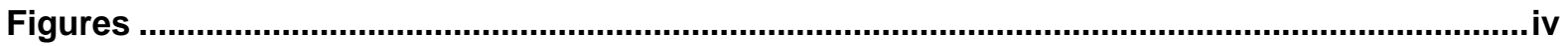

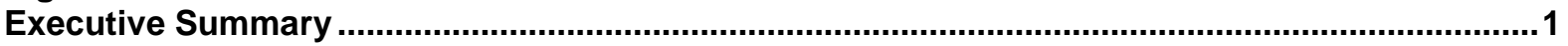

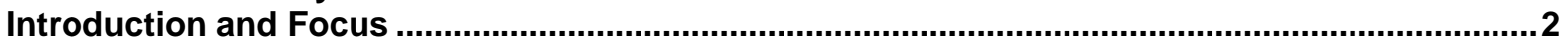

Policy assumptions and rationale for a decarbonisation narrative .............................................

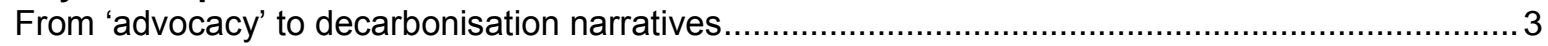

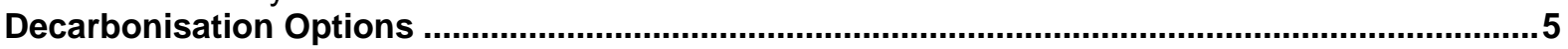

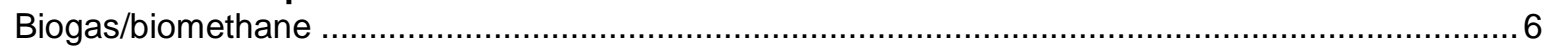

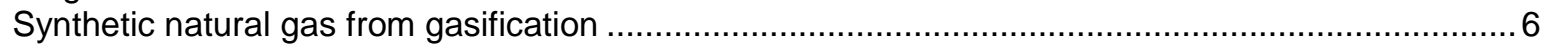

Hydrogen options: reforming plus CC(U)S, methane cracking ............................................... 8

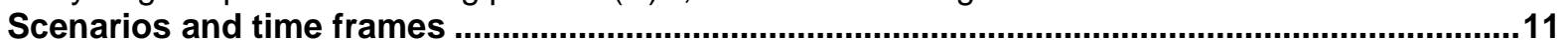

Value chain impacts on the role of gas in a fragmented community .......................................13

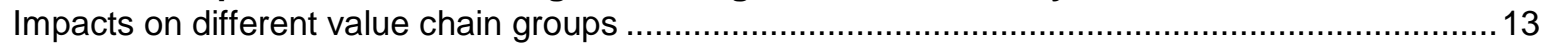

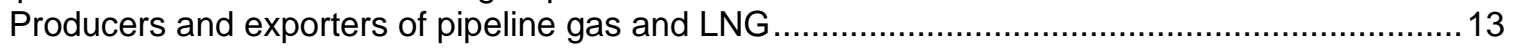

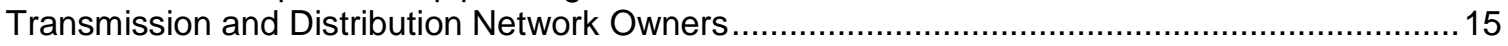

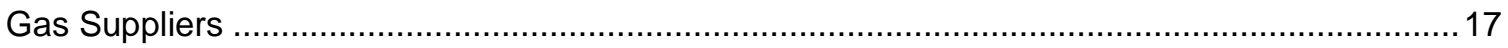

Storage, regasification, and gas-fired power asset owners .................................................... 17

Value chain cooperation and potential joint ventures ........................................................... 17

A regulatory revolution: changing the focus from competition to decarbonisation ....................18

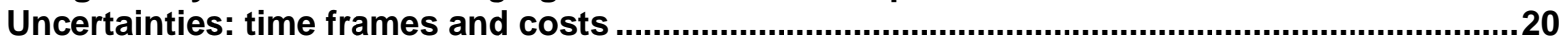

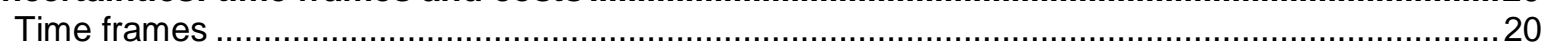

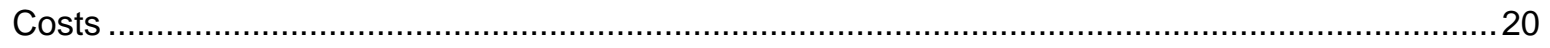

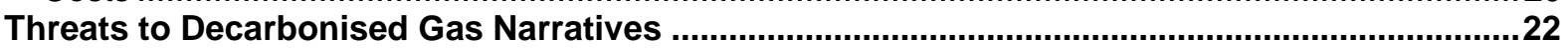

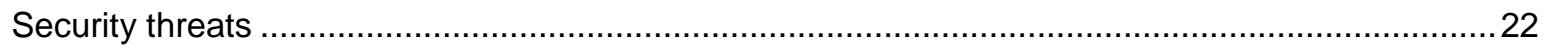

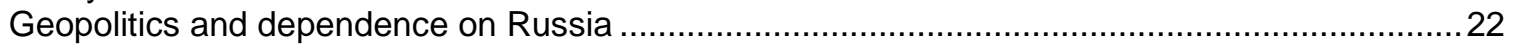

Fragmentation of unified networks carrying a homogeneous product.......................................22

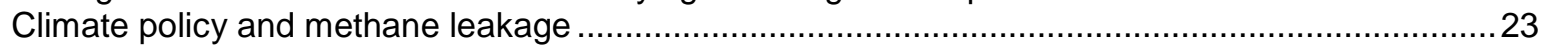

Commercial and regulatory threats - particularly for gas networks.............................................2

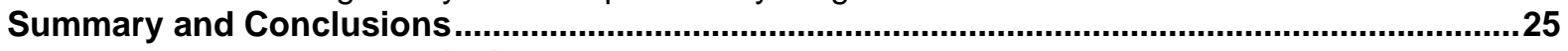

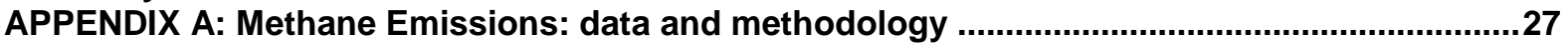

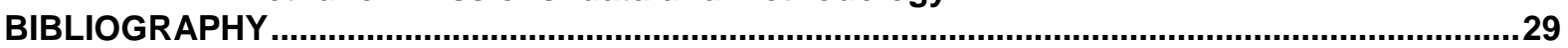

\section{Figures}

Figure 1: Overview of Anaerobic Digestion and Biomethane Upgrading Process ...............................

Figure 2: Estimates of European Biogas and Biomethane Production 2020-50* ...............................6

Figure 3: Overview of Power to Gas Options .............................................................................

Figure 4: Power-to-Gas Forecasts for Europe: 2030, 2040, and 2050 ......................................... 8

Figure 5: Integrated Carbon Capture and Steam Reforming Methane Plant .......................................

Figure 6: European Union: gas demand projections to $2050(\mathrm{bcm})$............................................... 12

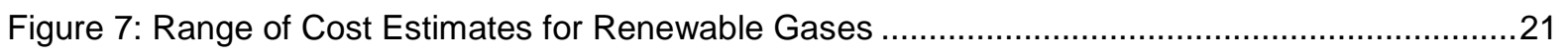

Figure A1: Breakdown of GHG emissions by element for oil and gas, 2017 .................................27 

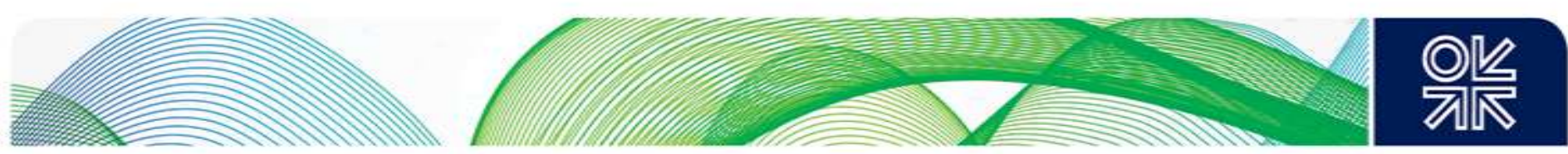

\section{Executive Summary}

From 'advocacy' to decarbonisation narratives

The advocacy narrative of the European Union (EU) gas community which focused on coal to gas switching and backing up renewables, while logical, has failed to convince governments, NGOs and media commentators that it can help achieve post-2030 decarbonisation targets. The gas community therefore needs to develop decarbonisation narratives, the components of which are the size and timing of developing commercial scale projects for biogas, biomethane, and hydrogen from power to gas (electrolysis) and reformed methane.

The choices which national governments, and regional and municipal authorities and companies will make - and the criteria which they will employ to make them - will differ within, as well as between, countries. The current model of gas markets transporting a homogenous product through a unified network will change significantly post-2030, which means there will not be a single European narrative but a range of narratives.

\section{Time horizons for EU gas demand under COP21 targets}

Projections of EU gas demand under COP21 carbon reduction constraints show a decline in methane demand starting in the late 2020s and accelerating over the following decades. In 2050, the maximum projected availability of biomethane and hydrogen from power to gas is equivalent to 25 per cent of European gas demand at late 2010 levels (most studies have much lower estimates). Therefore, if the gas industry is to maintain anything resembling current demand levels, there will be a need for very substantial volumes of hydrogen from reformed methane with carbon capture and storage (CCS). Neither of these technologies have been developed on a large scale, and CCS requires significant subsidies.

\section{Challenges for producers/exporters and networks}

These developments will have different impacts on the different parts of the value chain. Pipeline gas suppliers will need to progressively decarbonise their product if it is to remain saleable. LNG suppliers have the option of abandoning European markets in favour of those importing regions where decarbonisation policies have yet to make a major impact. However, networks face an existential threat unless they can maintain existing throughput while simultaneously adapting to a decarbonised product.

\section{Threats to the narratives and the need for a regulatory revolution}

Significant threats and challenges to these narratives are already visible. These include short term geopolitical concerns stemming from dependence on Russian gas, 'hydrocarbon rejectionism', and an inability of companies to plan and invest for a post-2030 decarbonised future. The longer-term challenge will be to persuade governments to shift the current policy framework from competition to decarbonisation which will require a 'regulatory revolution'. But the gas community needs to be clear that, although government funding and regulatory support will be needed to achieve decarbonisation targets, very substantial corporate investment in projects for which there is currently no business case, needs to be part of its narrative. The next 5-10 years will be a crucial period for the gas community to put forward, and demonstrate how it will deliver, credible decarbonisation narratives. Failure to do so is likely to result in the adoption of electrification rather than gas decarbonisation options. 

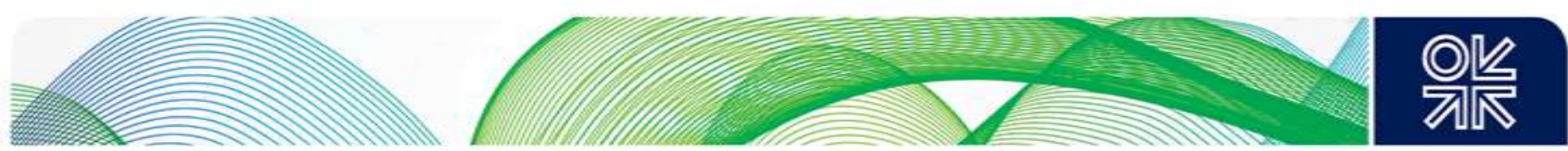

\section{Introduction and Focus}

This is the third paper in the series on the 'Future of Gas', following on from the author's previous studies ${ }^{1}$ which concluded that:

- unless methane can be decarbonised, the future of gas demand in Europe is decline after (and even possibly before) 2030, but much of the next decade could see robust demand and a need for more pipeline gas and LNG imports (and probably new import infrastructure) due to: declining domestic production, reduced use of coal and nuclear power, and gas use in tandem with rising renewable power generation;

- the future for national gas industries will be different, but in major European gas markets where governments are committed to rapid decarbonisation, the post-2030 outcome is predetermined if COP21 targets are to be met. These are the markets in the UK, Netherlands, Germany, France, Belgium, Italy, and Spain which, in the late 2010s, accounted for more than 75 per cent of EU gas demand ${ }^{2}$;

- for many other European countries (and especially outside Europe and the OECD in general) air quality, affordability and security concerns are much higher on the energy policy agenda than decarbonisation.

This paper argues that European gas stakeholders need to develop narratives which demonstrate that they can maintain a substantial place in decarbonising European energy balances post-2030. Because individual countries, regions, and sectors have potentially different futures and will therefore follow different decarbonisation paths, a common narrative for different countries and for different value chain players is not possible. Given the time required to develop and then roll out any largescale decarbonised methane, or non-methane gaseous alternatives, and the changes in legal, fiscal, and energy regulatory frameworks which these alternatives will require, time is short for the natural gas community to advance credible plans for consideration and acceptance by governments and the EU. The next important policy milestone will be the EU's Gas Package which is currently being formulated, with the intention for this to be finalised by the new Commission in 2020.

The structure of the paper is as follows: we first look at the policy assumptions and rationale for creating narratives. The next section examines the options, limitations, and timing of decarbonisation narratives, followed by an examination of published EU gas demand scenarios. Section 4 looks at the impacts of decarbonisation narratives on different parts of the value chain, in particular producers/exporters and network companies. This is followed by an examination of the regulatory changes which will be necessary for the narratives to be achieved, and the current uncertainties about time frames and costs. We then consider the security, climate policy and commercial threats to these narratives. The final section draws some conclusions.

\footnotetext{
${ }^{1}$ Stern (2017a) and (2017b).

${ }^{2}$ Two significant additional EU gas markets where decarbonisation commitments are less certain are Poland and Romania. In the wider Europe, the other very large gas market is Turkey.
} 

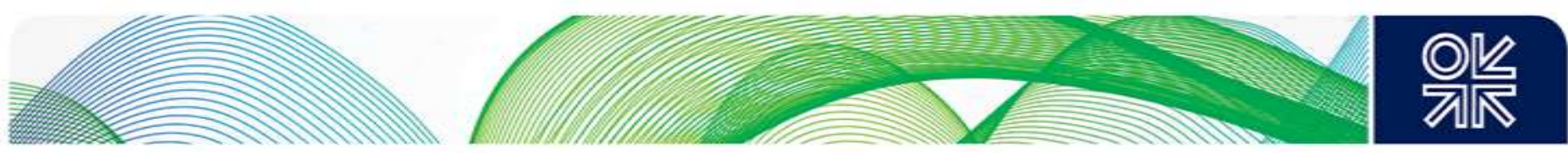

\section{Policy assumptions and rationale for a decarbonisation narrative}

The rationale for the European gas community to develop a decarbonisation narrative is based on the key assumptions that governments in most of the largest European gas markets are genuinely committed to COP21 decarbonisation targets and, although targets for specific future dates may be missed, they will neither abandon their commitment to large scale decarbonisation by 2050 , nor substantially delay its implementation. ${ }^{3}$ To assume otherwise is risky not only because it lets the gas (and other energy) industry 'off the hook' from taking any immediate action but also because this is proved to be incorrect (as this author believes it will be), governments may have decided that gas will not be part of a long term energy future and there will be insufficient time to make decarbonisation preparations before unabated methane needs to be phased out.

\section{From 'advocacy' to decarbonisation narratives}

The traditional 'gas advocacy' propositions are the carbon reduction benefits of coal to gas switching in power generation (and oil to gas in other sectors), and the advantages of gas in backing up intermittent renewables. Coal to gas switching provides 'low hanging fruit' for rapid, low cost carbon emission reductions, and this has already been demonstrated in both the UK (combined with a carbon floor price) and the US. ${ }^{4}$ In previous papers it was argued that although such arguments are highly persuasive from an analytical perspective, they do not address the priorities of national governments and the $\mathrm{EU}$ as a whole. This is because although they result in early emission reductions, these will not be sufficient to meet 2050 COP21 commitments. ${ }^{5}$ These arguments have also invited criticisms that they: 6

- lack any obligation on the gas industry to make decarbonisation efforts itself;

- ignore the issues of carbon lock-in and potentially high levels of methane emissions from the gas chain;

- ignore the rapid reduction in the costs of alternative methods of renewable energy back-up (specifically batteries) and the potential benefits of energy systems integration.

Therefore, despite continued repetition of the advocacy arguments, and irritation on the part of many natural gas stakeholders that policymakers have continued to iv cgnore their merits, it became clear that - in the major EU gas markets at least - a different message would be required. By 2018, presentations by the European Commission challenged the gas community to develop a narrative which would set out a future for gas, and specifically for methane, in decarbonising energy balances post-2030. ${ }^{7}$

\footnotetext{
${ }^{3}$ It is frequently observed that COP21 targets are not 'binding' on governments in the sense that there are no sanctions (other than embarrassment) if they are either not met or abandoned. While this may be correct, this paper takes the view that to rely on targets being delayed or abandoned would be an extremely risky strategy for value chain stakeholders in major European gas markets to adopt.

${ }^{4}$ For details see Stern (2017a), pp.21-2. The most often-cited example of which is the UK where the introduction of a significant carbon floor price (and increased international coal prices) has led to coal-fired power stations being progressively phased out before their policy-dictated retirement in 2025 , resulting in substantial reductions in carbon emissions. In the US, the substitution of low cost shale gas for gas in power generation has had similar results.

${ }^{5}$ Eurogas (the European trade association) continues to point out - using the EU's PRIMES modelling - that switching from coal and oil to gas would 'exceed the EU's 2030 GHG reduction target by 5 per cent. This will provide time for developing new cost-efficient options for 2050'. https://gaswindandsun.eu/ accessed December 28, 2018. Eurogas also recognises the importance of a wider range of options: Braaksma (2018). The German Gas and Water Association (DGVW) suggests three types of switching: fuel (from more carbon-intensive sources), content (towards decarbonised gases), and modal (sector coupling and efficient integration). Lincke (2018).

${ }^{6}$ These views can be found in: Corporate Energy Observatory (2018), Friends of the Earth Europe (2017), Oilchange International (2017); Hanna et al. (2018).

${ }^{7}$ Presentations by Klaus-Dieter Borchardt (Director of the Internal Energy Market at DG Energy) at the European Gas Conference and the FLAME Conference in 2018. Interviews with Borchardt which set out the Commission's view on the future role of gas can be found at Florence School of Regulation (2018) and (2019).
} 

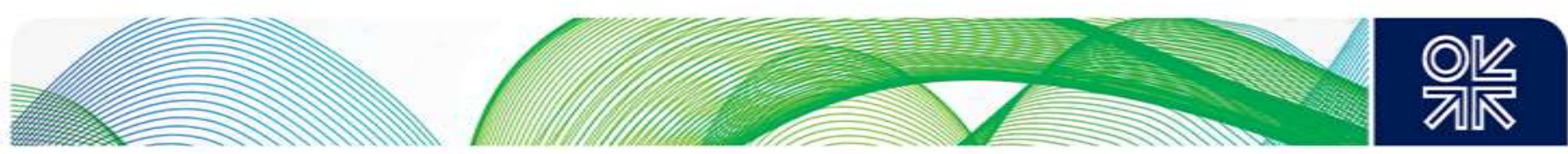

This challenge to the gas community is highlighted by differing estimates of the costs of meeting decarbonisation targets by means of a combination of electrification and gas compared with electrification alone. A range of studies concluded that a gas/electrification combination would be lower cost than electrification-only options, and that a zero-carbon gas future would be significant lower cost than an all-electric alternative. ${ }^{8}$ There are contrary arguments that 'renewable electricity is expected to be consistently cheaper than fossil gas, let alone renewable or decarbonised gas before the end of this decade. Cost projections for electric vehicles are on a steep downward trajectory and residential heating is gradually being electrified'. ${ }^{9}$ However, these general and European-level assessments are problematic in terms of their relevance for individual countries. Decarbonisation options such as coal to gas switching, hydrogen (with or without CCS) and biogas/biomethane may be important, immediate, and low cost in some countries - and particularly certain regions of countries - but marginal or irrelevant in others.

To maintain traction for its claim for the continued relevance of gas post-2030, the European gas community will need to move from its previous advocacy position to a decarbonisation narrative which needs to include the following components:

- commitment to a range of actions in relation to reducing the carbon (and methane) footprint of natural gas over a specific time period to fit with national carbon reduction targets;

- a time frame for selecting and then rolling out low or zero carbon gas projects nationally or through specific networks (or regions);

- technical, legal, fiscal, and carbon price/tax frameworks which need to be created by the European Commission, national governments, and regulators in order to achieve these options.

Decarbonisation options for European gas markets will be very different in different countries - and within regions of countries - and for this reason, as well as the fragmentation of the gas value chain which has resulted from liberalisation (see below), this paper refers to a European gas community with different interests and options rather than a gas industry which suggests a cohesive group with a unified purpose. This is why there is no single narrative for gas decarbonisation, but different narratives which will depend on existing infrastructure, available resources, geographies, and policies (both national and regional).

\footnotetext{
${ }^{8}$ For example CERRE (2018), Pöyry (2018), Ecofys (2018). See also Florence School of Regulation (2019), where the Director for the Internal Energy Market at DG Energy rejects an all-electric future as 'not cost-effective and technically impossible'. ${ }^{9}$ Fischer (2018), 23-4.
} 

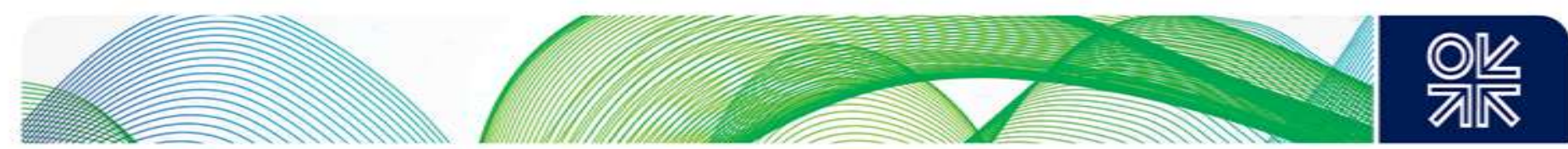

\section{Decarbonisation Options}

The options for decarbonising gas are relatively well-known and can be divided into:

- Biogas and biomethane, and bio-SNG (or syngas) via gasification;

- Hydrogen and/or syngas from renewable power: power to gas (P2G), power to methane (methanation);

- Hydrogen from methane via: steam reforming (SMR) or auto-thermal reforming (ATR) with carbon capture, utilisation and storage (CC[U]S); methane cracking with storage/utilisation of solid carbon.

These options have created terminology based on colours (green, blue, and grey ${ }^{10}$ ) and carbon content (zero and low), as well as the terms 'renewable gas' and 'clean hydrogen' which are confusing rather than helpful, particularly as there are technical difficulties in determining the volume of carbon dioxide emitted by different processes. The European Commission has proposed extending 'guarantees of origin' (GOO) to different categories of renewable gas and these are likely to become mandatory, particularly for those claiming that their gas should be considered 'green'. ${ }^{11}$ The European Commission's Committees for Gas and Electricity Standardisation (CEN and CENELEC) have made considerable progress in defining standards for biogas, biomethane, and hydrogen. ${ }^{12}$

Detailed analysis of these options and projects which are both operating and planned can be found in other publications, and only a brief description and estimates of the potential are provided here. ${ }^{13}$

\section{Figure 1: Overview of Anaerobic Digestion and Biomethane Upgrading Process}

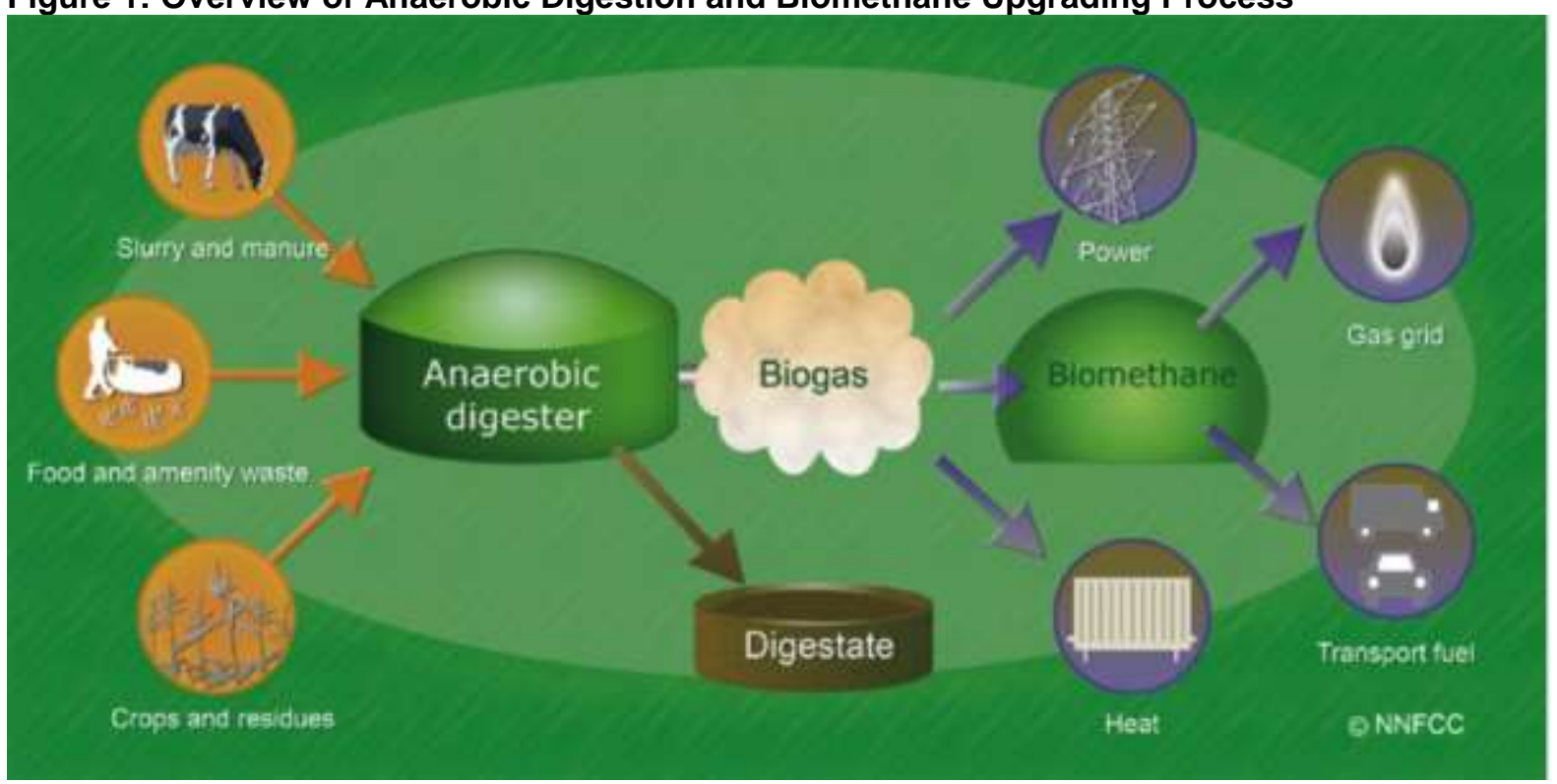

Source: Lambert (2017), p. 3. From the UK Anaerobic Digestion Portal.

\footnotetext{
10 These generally (but not reliably) refer to hydrogen produced from: renewable energy (green); reformed methane with CCS (blue); and reformed methane without CCS (grey).

${ }^{11}$ Lopez-Nicholas (2018), Deputy Director of the renewables policy division at DG Energy notes that 'there is no definition of renewable gas as such'.

12 CEN (2018).

${ }^{13}$ For more detail on the different options see Fischer (2018).
} 

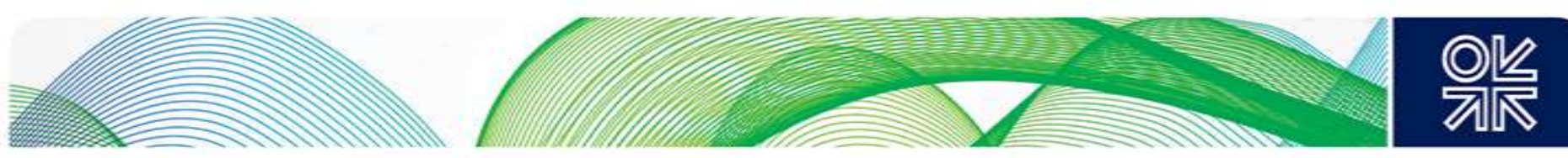

\section{Biogas/biomethane}

The primary method of biogas production is the biological breakdown of organic material in the absence of oxygen known as anaerobic digestion. Biogas can be upgraded to biomethane by a variety of methods (absorption, adsorbtion, methane filtration, and cryogenic separation) which can then be used interchangeably with natural gas. ${ }^{14}$ Figure 2 shows different estimates of biogas production up to 2030 and biomethane production up to 2050. The most optimistic of these sees the possibility of $98 \mathrm{bcm}$ of biomethane from biomass sources by $2050 .{ }^{15}$ The Entsog scenarios for 2040 are very substantially lower, showing only $20-50 \mathrm{bcm}$ of biomethane production in 2040 .

Figure 2: Estimates of European Biogas and Biomethane Production 2020-50*

$$
1200
$$

$1000 \longrightarrow \frac{\text { GC Biomethane }}{2}$

800

$\sum_{\xi}^{\xi}$

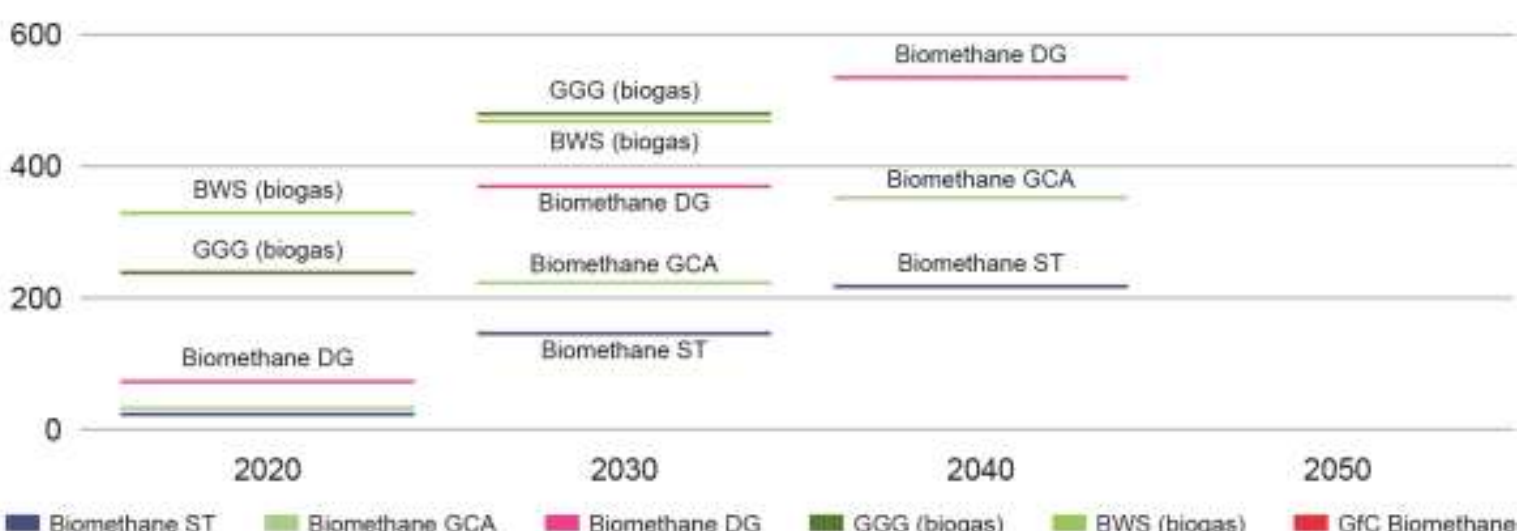

${ }^{*} 10 T W h$ is roughly equal to $1 \mathrm{bcm}$ of gas. ST, GCA and DG are Entsog scenarios.

Source: Entsog/TNYDP (2018), p.41.

\section{Synthetic natural gas from gasification}

Synthetic natural gas (SNG) can be produced from gasification of waste via a thermo-chemical process using biomass and/or other waste as a feedstock. ${ }^{16}$ This technology is still at an early stage of development. A French study has concluded that 40 per cent of the country's gas demand in 2050 will be produced from 'pyrogasification from wood and its derivatives, refuse-derived residues and a low proportion of agricultural residues'. ${ }^{17}$

\footnotetext{
14 See Lambert (2017) for more detail.

15 The $98 \mathrm{bcm}$ figure is comprised of $63 \mathrm{bcm}$ from anaerobic digestion and $35 \mathrm{bcm}$ from thermal gasification. The largest single biomethane contribution is from maize silage and triticale produced as sequential crops, based on an optimised Italian concept 'Biogasdoneright'. Ecofys (2018), pp.13-21.

${ }^{16}$ Lambert (2017), pp.3-4 explains the process in detail.

17 ADEME (2018), p.6.
} 

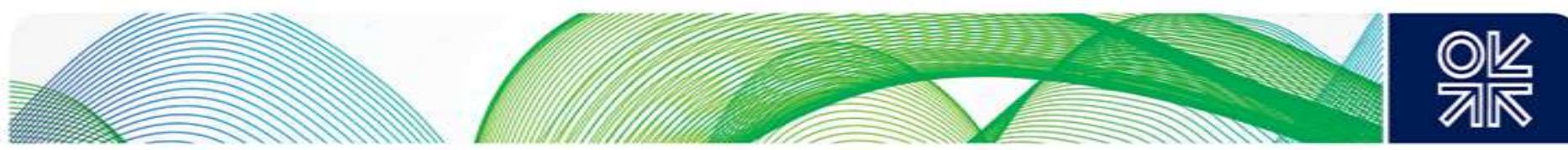

Power to Gas (P2G) relies on the principle of electrolysis: using electricity to separate water into its component parts of hydrogen and oxygen. Experimental pilot plants were developed in the late 1990s and early 2000s, and potential for widespread commercial deployment has been created due to the availability of renewable power generation in excess of immediate electricity demand. ${ }^{18}$ An overview of these options is shown schematically in Figure 3, but the current progress of the technology and projects suggests relatively small volumes unless a very large surplus of low/zero cost renewable electricity is available, or dedicated off-grid renewable energy systems are built in regions with high wind and solar resources. ${ }^{19}$

\section{Figure 3: Overview of Power to Gas Options}

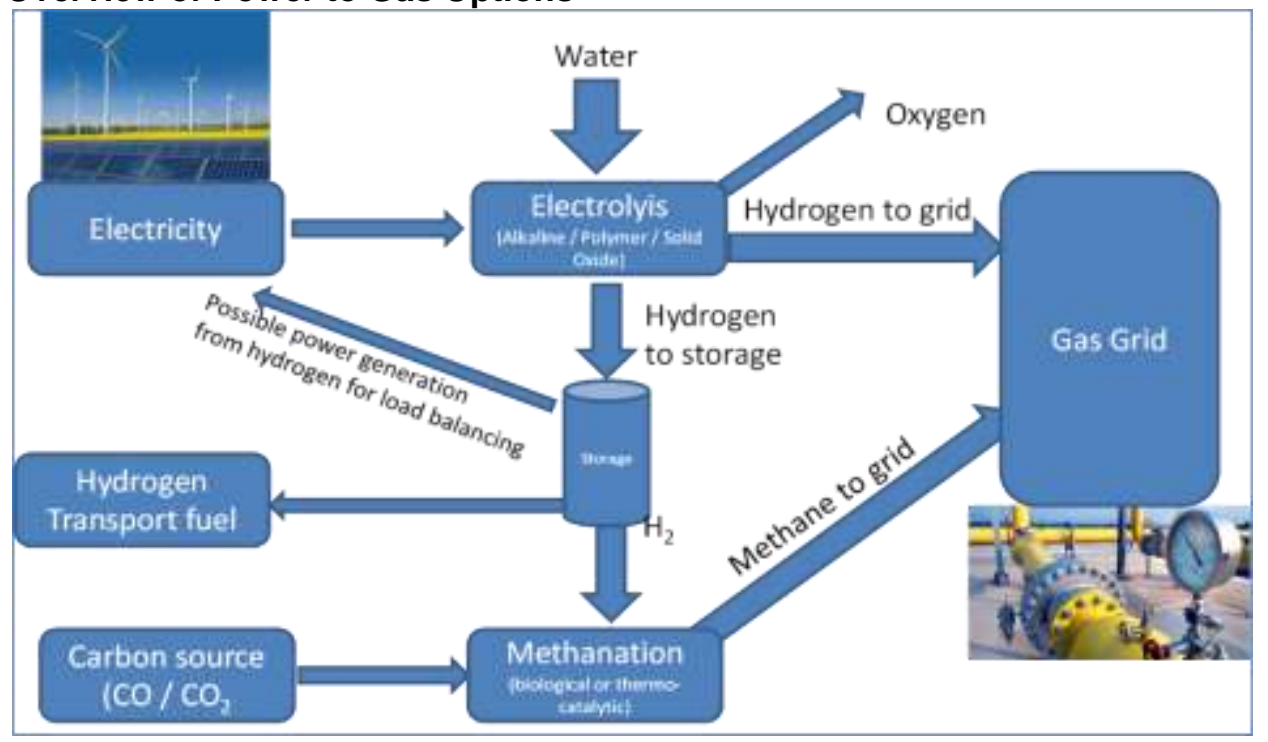

Lambert (2018a), Figure 2, p.3.

Figure 4 shows estimates for European power to gas production up to 2050. The Ecofys (GfC) estimate of $24 \mathrm{bcm}$ of renewable hydrogen from wind and solar power in 2050 is two and a half to five times higher than Entsog's scenarios for 2040. ${ }^{20}$

\footnotetext{
${ }^{18}$ Lambert (2018a).

${ }^{19}$ For more detail on P2G see Lambert (2018a); European Power to Gas Platform (2018).

${ }^{20}$ Ecofys (2018), p.9.
} 

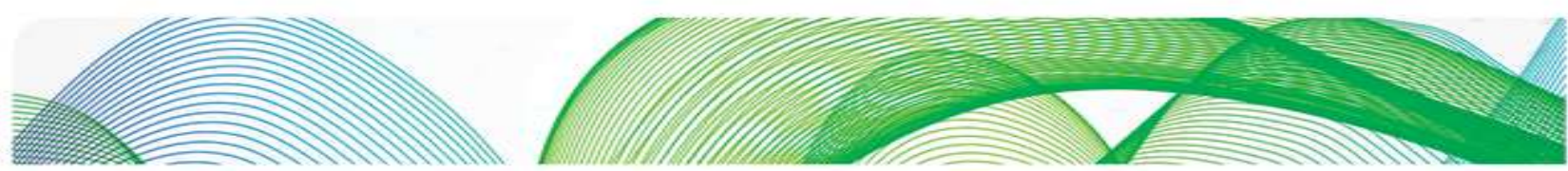
은

Figure 4: Power-to-Gas Forecasts for Europe: 2030, 2040, and 2050

300

250

200

$\sum 150$

100

50

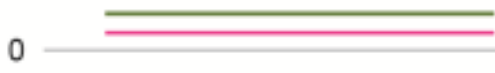

2030

2040

2050

- P2G DG $\square$ P2G GCA $=$ GFP2G

Source: Entsog/TNYDP (2018), Figure 23, p.44.

An important conclusion from a review of the current progress of these options is that they might be adequate if gas' role in future European energy balances is only to provide daily and seasonal back up renewable energies. ${ }^{21}$ But to maintain anything close to the scale of the gas market in the late 2010s, even the highest estimates of biogas, biomethane, and power to gas would need to be supplemented with the reforming of methane into hydrogen accompanied by carbon capture, utilisation and storage. It needs to be stressed that this is an overall European conclusion. It does not exclude - and indeed it specifically envisages - the possibility that individual countries, and particularly regions of countries, will convert existing gas networks to a mixture of methane, biomethane, and hydrogen, or building new networks specifically to transport hydrogen.

\section{Hydrogen options: reforming plus $\mathrm{CC}(\mathrm{U}) \mathrm{S}$, methane cracking}

DNV GL estimated the following shares for European hydrogen production in 2017: gas 68 per cent, oil 16 per cent, coal 11 per cent and electricity (electrolysis) 5 per cent. ${ }^{22}$ While industrial utilisation of hydrogen is common in many parts of the world, it is mainly confined to the refinery sector where the product is used on site where it is manufactured, or transported short distances to limited numbers of industrial customers. Large scale methane reforming with carbon capture to produce hydrogen for network distribution to residential and commercial customers (Figure 5) would be a completely new development.

\footnotetext{
${ }^{21}$ The impression sometimes given by European Commission officials is that this may be the only role for gas in decarbonised energy markets, see Bowden (2018).

22 DNV GL (2018), Slide 12. The IEA estimates that around 50 per cent of global hydrogen production is generated from natural gas by steam methane reforming, 30 per cent from cracking oil products (mainly naphtha) in the refining and chemical sectors, and 18 per cent using coal gasification (mainly in China). IEA (2018), pp. 507-8.
} 

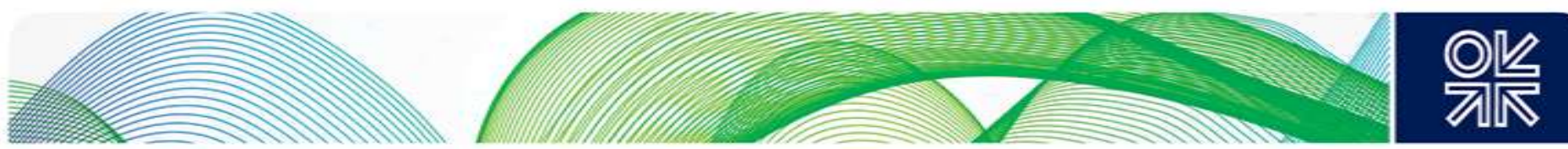

Figure 5: Integrated Carbon Capture and Steam Reforming Methane Plant

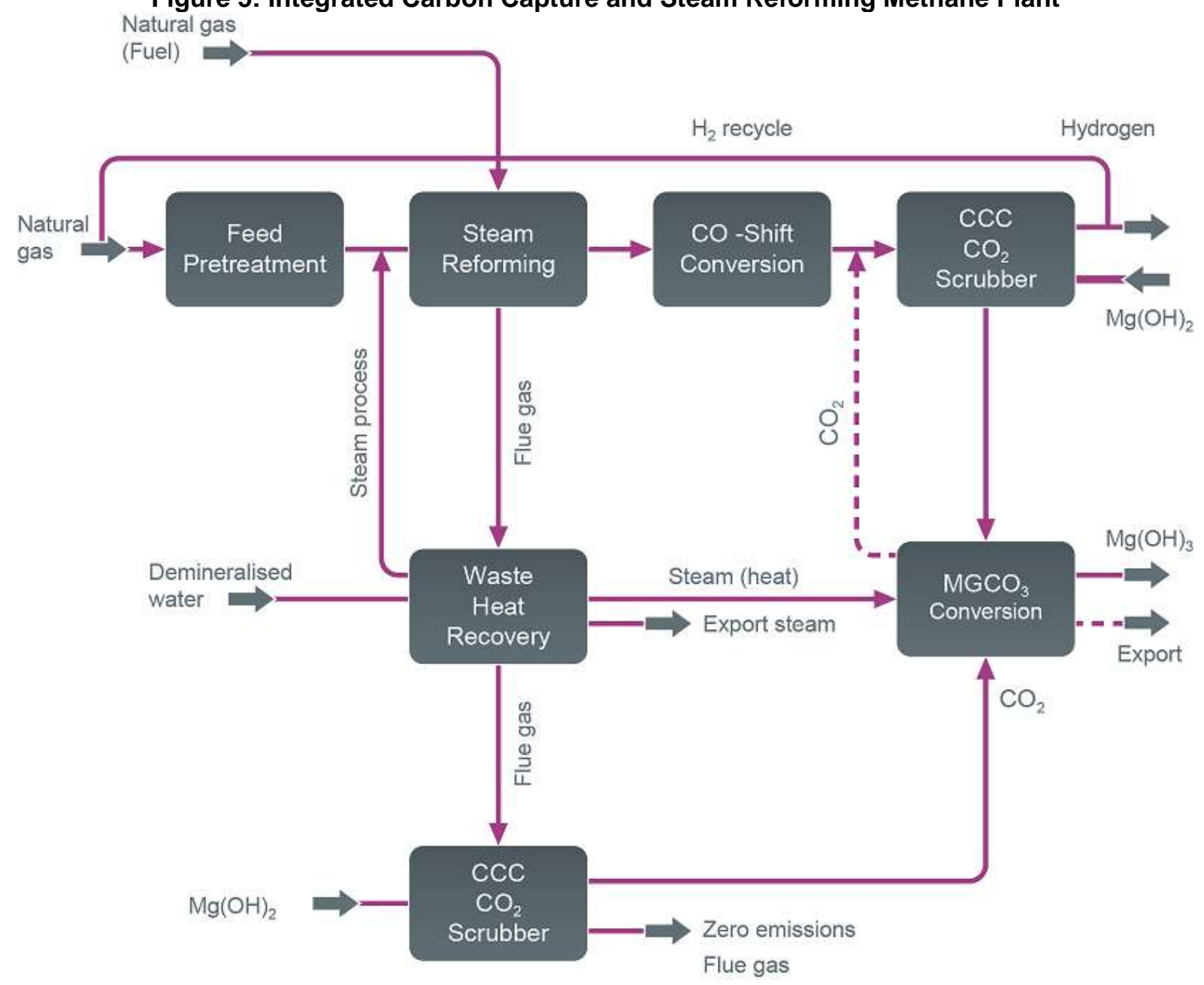

Source: Leeds City Gate H21, Image 11.10, p.359

There are currently only two operational natural gas-based carbon capture projects in Europe, both of which are at Norwegian gas fields (Sleipner and Snohvit) with $\mathrm{CO}_{2}$ injection directly into offshore reservoirs, although there are a range of other projects at the feasibility study or test stage in six other European countries. ${ }^{23}$ At the moment large scale methane reforming to hydrogen with CCS is under serious consideration only in the UK, while in southern Europe there is greater emphasis on biogas and biomethane development. ${ }^{24}$ The principal reason for this is the availability (or otherwise) of suitable offshore structures for carbon storage; countries such as the UK and the Netherlands have offshore structures (depleted gas fields and aquifers) which are suitable for storing carbon dioxide. Furthermore, hydrogen initiatives can be combined with storage in UK or Norwegian offshore

\footnotetext{
${ }^{23}$ IOGP (2018). The countries are: Belgium, France, Netherlands, Sweden, Republic of Ireland, and the UK. For a global view of CCS, see CCS Institute (2018).

${ }^{24}$ This is not to argue that biomass and biomethane are ignored in northern Europe. A 2018 analysis of future heat options for the UK's National Infrastructure Commission found that biomethane grid injection and off-grid biomass heating were both 'low regrets opportunities'. Element Energy (2018). By contrast a 2018 review of German hydrogen options focuses on power to gas. Lohmann (2018).
} 

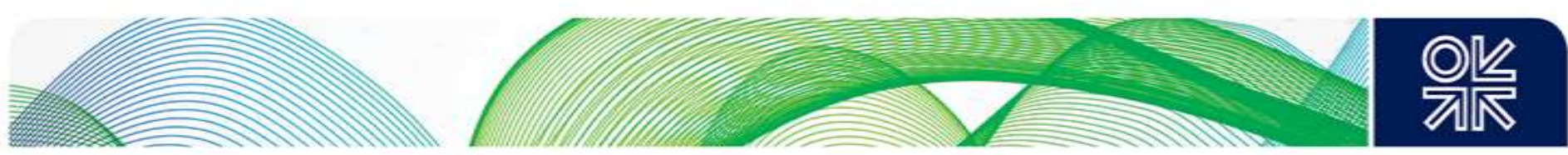

structures. ${ }^{25}$ In central and southern Europe, lack of access to offshore storage structures means that the methane reforming option is logistically problematic and therefore less commercially viable.

The emphasis on offshore structures is the result of onshore carbon dioxide storage being considered politically impossible in major European gas markets due to environmental opposition. The rationale for such opposition is not entirely clear but has been accepted, which means that large capacity offshore structures - with pipelines leading to those structures - will be required. It also suggests that large scale CCS must take place pre-combustion rather than post-combustion. There are strong logistical advantages to gas producers reforming methane and producing hydrogen either at the field or where the gas is landed onshore. The advantage of pre-combustion CCS would be that only offshore carbon dioxide pipelines would be needed. ${ }^{26}$ The potential disadvantage would be that all networks and customers in those regions would need to be converted to hydrogen, unless a further step was taken to methanise the hydrogen into syngas onshore which would add to efficiency losses and therefore to costs. ${ }^{27}$ An alternative method of utilising hydrogen (whether produced from power to gas or reformed methane) is by converting it into ammonia which is much easier to store and transport. ${ }^{28}$

An additional method of hydrogen production is methane cracking which splits methane into hydrogen and a solid carbon residue - carbon black - which can then be used in a range of industrial processes. This could resolve some of the problems and costs of carbon storage, but the extent and scale of the utilisation options for carbon black are uncertain and large scale storage would still be required. This process is currently at the laboratory testing stage and it remains to be seen how quickly it will develop. ${ }^{29}$

\footnotetext{
${ }^{25}$ Two of these projects - North of England H21 (H21 NOE 2018) and Magnum power station (Equinor 2017) are being developed in collaboration with Equinor (a large-scale natural gas exporter to both countries). The the HyNet North West project in the UK is being developed by Cadent. https://hynet.co.uk/

${ }^{26}$ However pre-combustion is not trouble-free, as demonstrated by the delays to the CCS project at Australia's Gorgon field. Smyth (2018).

${ }^{27}$ The STORE\&GO plant at Falkenhagen in Germany converts wind energy into hydrogen and adds $\mathrm{CO}_{2}$ from a nearby bioethanol plant to produce SNG. This is part of an EU-supported international research project. https://www.storeandgo.info/demonstration-sites/germany/

${ }^{28}$ For a study of the electrolysis-hydrogen-ammonia route see: Institute for Sustainable Process Technology (2017). The IEA is somewhat less enthusiastic about ammonia noting its toxicity and the potential for escape of uncombusted fractions. IEA (2018), p. 509

${ }^{29}$ For further information see Karlsruhe Institute of Technology (2018) and Fincke et al. (2002).
} 

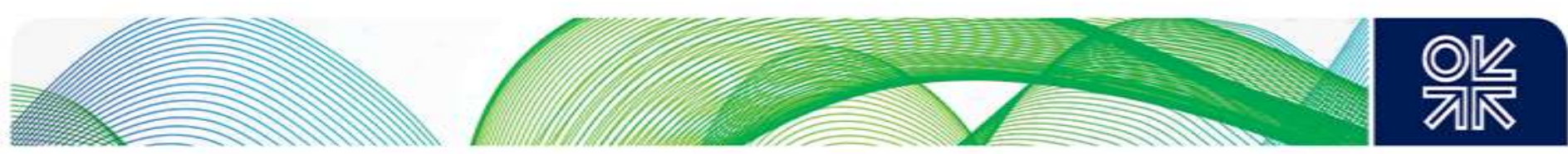

\section{Scenarios and time frames}

A very important aspect of the narratives being developed concerns the time frame of decarbonisation. Examination of modelling studies in previous publications showed a consensus that, in order to meet COP21 targets, European methane demand will start to decline significantly in the 2030s and accelerate thereafter. Studies published in 2018 by oil and gas companies include the Shell Sky scenario which is designed to achieve a 'less than two degrees' world (ie compatible with the Paris targets) and extends to 2100. The Sky scenario shows European gas demand stable up to 2030 with significant decline thereafter, although even in 2050 demand is only 33 per cent below 2015 levels.

$\mathrm{BP}$ has five scenarios for global gas demand but only gives regional projections in two of them. For Europe the reference scenario shows a 6 per cent increase in demand by 2040 compared with 2016, while the alternative scenario shows a fall of 0.1 per cent per annum for that period. ${ }^{30}$ One of the Outlook's key uncertainties is the risk to gas demand, pointing out that gas growth could be challenged by both stronger and weaker environmental policies: the scenarios include a 'Faster Transition' and 'Even Faster Transition' to low-carbon energy ('Renewables Push'), or slower switching from coal to gas ('Less Gas Switching') and lack of support for carbon pricing. The 'Even Faster Transition' scenario results in 2040 global gas demand slightly below its 2016 level. $^{31}$

Equinor's three scenarios show European gas demand stable or slowly rising up to 2030. By 2050, demand has contracted slightly in two of the scenarios, but in 'Renewal' - which is a policy-driven scenario where COP21 targets are met - it is less than half its 2015 level. ${ }^{32}$ The IEA's 2018 World Energy Outlook has a similar trajectory to Sky for its New Policies scenario but post-2030, its Sustainable Development (2 degrees) scenario is very close to Equinor's Renewal.

Figure 6 brings all of these projections of European gas demand together. The detail is problematic because of some statistical differences (and some intervening years have been added by the author), but the overall picture is relatively positive for gas demand, and therefore gas suppliers, at least up to the second half of the 2020s. Post-2030, demand decline accelerates and it is significant that only two of these projections - Equinor and Shell - extend beyond 2040 since it is clear that, if decarbonisation targets are to be met, the decline in demand will further accelerate beyond that date. This should alert the European gas community, and particularly networks, that commercial scale decarbonised gas projects need to be ready to roll out by the mid to late 2020s, because of the lead times which will be necessary, particularly if there is a need to convert significant numbers of customers to a different gas quality or type. A serious problem is that there is currently no 'business case' for investing in these projects, specifically no expectation that they will earn a commercial return, and this will need to be addressed through policy and regulation (see below).

\footnotetext{
${ }^{30}$ BP Energy Outlook 2018 Edition. www.bp.com/en/global/corporate/energy-economics/energy-outlook/energy-outlookdownloads.html., pp. 80-87. Regional data can be found in the data tables which accompany the main report.

${ }^{31} \mathrm{lbid}, \mathrm{p} .86$. There is no regional breakdown of the data. The other four scenarios result in demand growth of $0.5-1.5 \% / y e a r$ from 2016-40.

32 Equinor, Energy Perspectives 2018: long term macro and market outlook, p.44. The three scenarios are: Reform, Renewal, and Rivalry, with policy and the geopolitical environment being the major differences between them.
} 

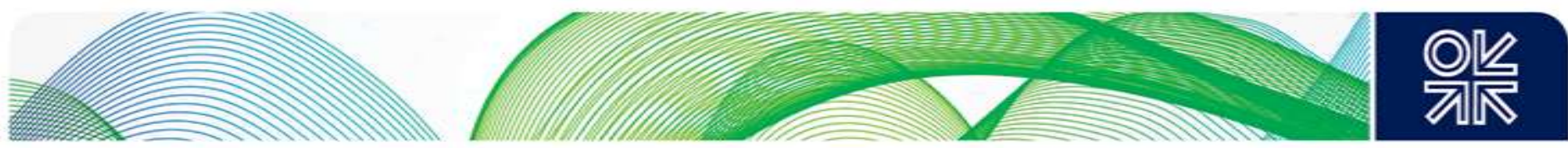

Figure 6: European Union: gas demand projections to 2050 (bcm)

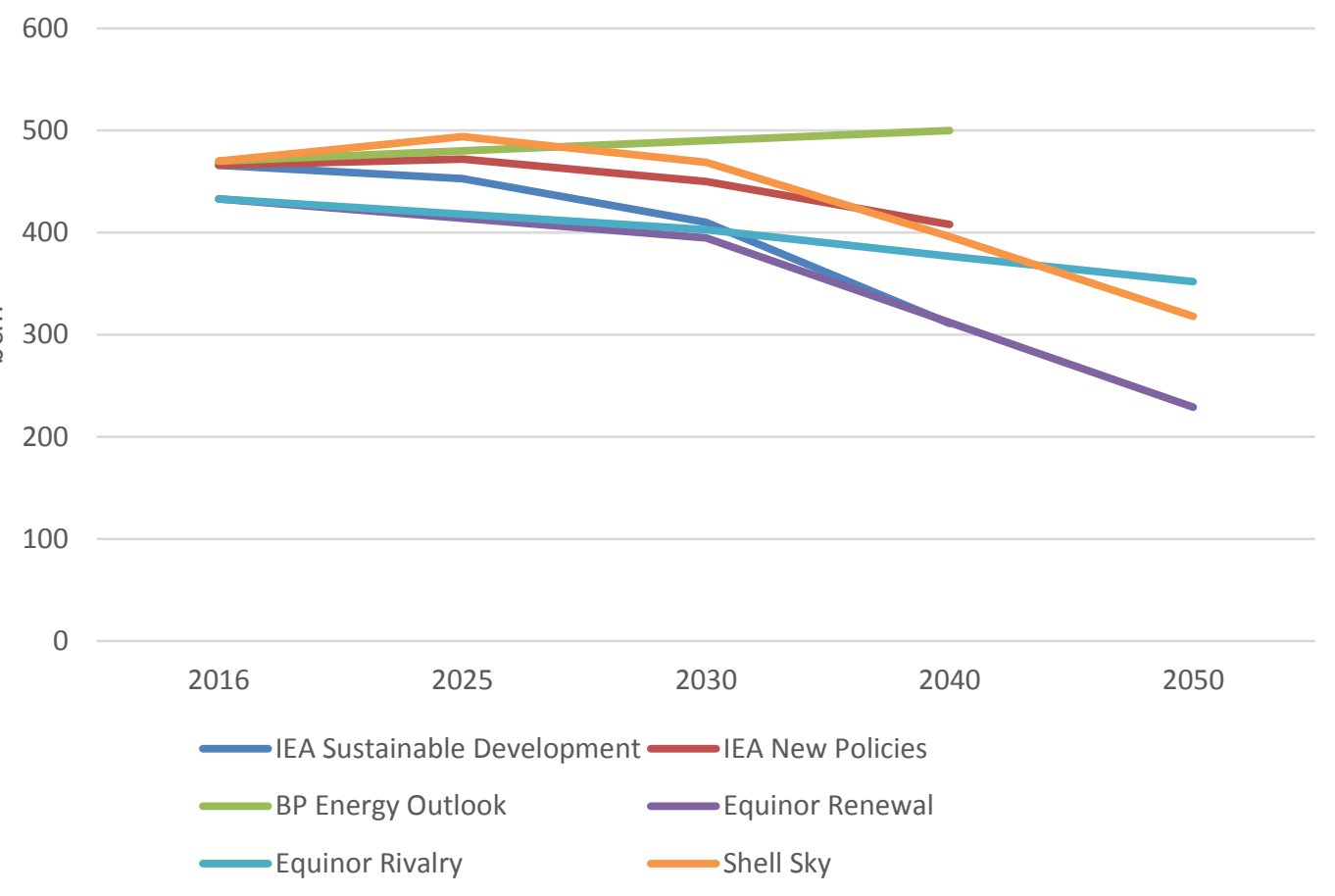

Sources: IEA (2018), pp.550-551. BP (2018), p.54. Equinor (2018), p.57. Shell Sky Scenario. 

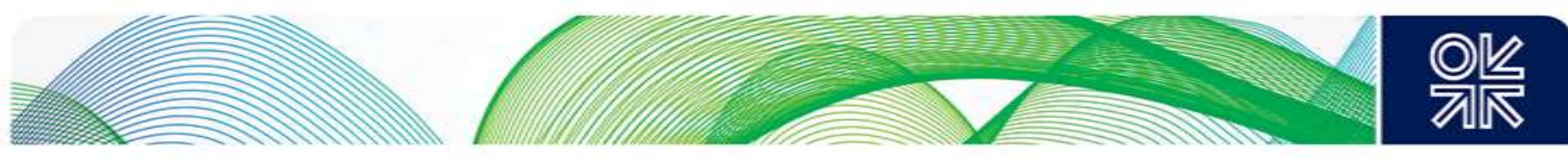

\section{Value chain impacts on the role of gas in a fragmented community}

Previous research showed how the fragmentation of the gas value chain has substantially complicated the task of the gas community to cooperate in the decarbonisation of gas markets. ${ }^{33} \mathrm{In}$ the monopoly era, a decision to make fundamental changes to the value chain could be taken by the dominant merchant transmission company in cooperation with suppliers (producers or exporters) and with government approval. Liberalisation has divided the gas value chain into different segments, and regulation requires the network and supply functions of the industry to be operated (and often owned) by different companies. The different segments of the liberalised value chain therefore have different commercial interests:

- Producers and exporters want to sell large quantities of methane - which has required significant investments to discover and develop - over long time periods (if possible) underpinned by long-term contracts;

- Network companies want to maximise the life and the capacity of their assets by transporting products, currently methane but in the future potentially biomethane or hydrogen;

- Suppliers and traders which have power and other energy-related businesses have the option of switching from gas to power, and are therefore not bound to a long-term future of methane (or other gas) except to the extent that they are owned by gas producers and exporters;

- Owners of gas-fired power stations, LNG regasification terminals, and gas storages will seek to maximise the productive life of their assets. These are time-limited although power plants and storages have the potential to use decarbonised gases. But again, regasification assets are often owned by producers and exporters.

Therefore it is producers and, to a lesser extent, regasification terminal and storage owners, who have an interest in a methane-specific future post-2030. By contrast network owners have a strong interest in ensuring that gas (but not necessarily methane) is maintained in energy balances at levels which ensure their assets remain significantly well-utilised over the next several decades.

Decarbonisation of gas markets will require significant value chain cooperation because of the need to ensure that networks and customers would be able to accept a decarbonised gas supply, and arrangements are in place for dealing with capturing, transporting, and storing carbon dioxide. Given the lead times for gas decarbonisation, value chain agreements would need to be put in place some (and in the case of hydrogen many) years ahead of projects being implemented. This would also involve substantial changes in both the existing and the development of new regulation to which we return below.

\section{Impacts on different value chain groups}

\section{Producers and exporters of pipeline gas and LNG}

As stated in the Introduction, producers and exporters of pipeline gas and LNG to Europe have good expectations of growth in the need for additional supply (despite the fact that this may be accompanied by flat or falling demand) over the next decade due to the likelihood that domestic production will fall faster than demand. However, anticipation that serious demand decline could start by the late 2020s and intensify significantly thereafter (Figure 6), raises questions for how long beyond the mid-2030s it will be possible to sell large volumes of unabated methane in major European gas markets. While the mid-2030s may seem a very long commercial time horizon, it is short in terms of the arrangements required for new exploration and infrastructure investment required

\footnotetext{
${ }^{33}$ Stern (2017a), pp.15-18.
} 

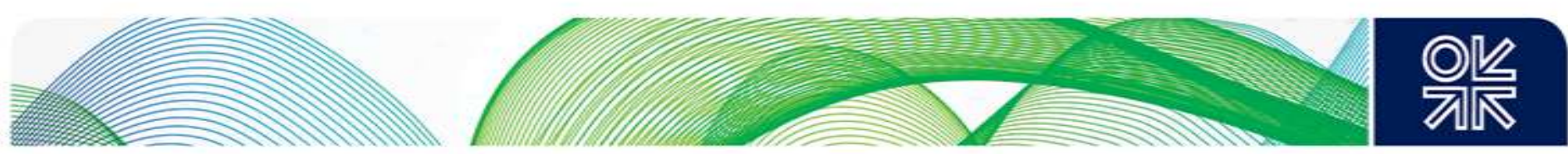

to develop new large-scale methane supplies requiring new long-distance pipelines or greenfield LNG projects. And it is certainly not a long time-horizon to ensure that energy networks, markets, and customers will be ready to receive decarbonised gas.

Large pipeline gas and LNG projects are designed to run for more than two decades, and developers of projects, particularly those which have yet to take a final investment decision (and therefore will not start operating until the second half of the 2020s), will need to consider the potential decline of European demand for unabated methane in the 2030s. National gas communities will need to consider the possibility that their governments may specify targets - and potentially deadlines - for phasing out unabated methane, similar to the plans in many EU countries to phase out coal by the early/mid 2020s.

A reduction of opportunities for methane sales in Europe, would require pipeline exporters to progressively decarbonise their product. LNG exporters would have the option of giving up their European markets and selling their product elsewhere in the world but, although that is a possibility, it is likely to be unattractive for most LNG sellers for several reasons. Firstly, European markets are significantly profitable with large creditworthy customer bases and many exporters have invested in LNG terminals (and associated infrastructure) and have sales organisations, which would be potentially stranded should they decide to give up their European gas business.

Furthermore, it can be argued that in order to meet COP21 targets, many other parts of the world will have to consider decarbonising methane post-2040, and it could be valuable for producers and exporters to gain experience in Europe. For LNG exporters, a potentially revolutionary question is whether they should consider reforming methane into hydrogen and storing the $\mathrm{CO}_{2}$ close to where it is produced (in depleted fields) and shipping hydrogen rather than LNG to European markets. ${ }^{34}$ For those whose principal LNG market is (or will be) Europe post-2030, it is not too early to be considering such an option.

Any decision about unabated pipeline gas or LNG sales in the 2030s and beyond must take into account the life of gas reserves of different countries and companies. ${ }^{35}$ Production projections for Norwegian fields suggest that exports can be maintained at around half of 2017 levels into the mid2030s, but production from fields yet to be discovered may allow production and exports to be maintained at around 80 per cent of those levels. ${ }^{36}$ At the time of writing, Equinor has shown the most interest in pursuing a methane/CCS pathway, partnering with both the UK's North of England H21 and Dutch Magnum power station projects (noted above). ${ }^{37}$

Current levels of Russian, North African, Caspian and Middle East, and probably US, reserves-toproduction ratios would allow for substantial exports of gas and LNG post-2040. ${ }^{38}$ The gaseous reserves of many of these countries and regions significantly exceed their liquid hydrocarbon reserves. But current export levels, installed infrastructure, and commercial and geopolitical expectations, suggest that only Norway, Russia, Qatar, and (possibly) the US are likely to be exporting substantial volumes of pipeline gas and/or LNG to Europe in the 2040s. Of these only Norway and Russia have strong physical (pipeline) links with Europe, whereas Qatari and US

\footnotetext{
34 The first global examples of large-scale shipping of hydrogen are the Japanese initiatives to import methane-based hydrogen from Brunei, and coal-based hydrogen from Australia in the early 2020s; both countries are traditional LNG exporters. There are plans to create hydrogen export hubs on both the west and east coasts of Australia. Bogle (2018). See Chiyoda (2018) for information on the Brunei-Japan project. An estimate of costs for a range of options to produce hydrogen in Australia with shipping to Japan can be found in IEA (2018), Box 11.6, pp.510-11. For details of Japan's hydrogen strategy see Nagashima (2018).

${ }^{35}$ It would also need to consider contracts currently in force, but only a few of these extend further than the early 2030 s which is when Figure 6 shows the start of steep demand decline.

${ }^{36}$ Hall (2018), Figure 4, p.6.

${ }^{37}$ H21 NOE (2018); Equinor (2017).

${ }^{38}$ For reserves and reserve to production ratios at end-2017 see BP (2018), p.26.
} 

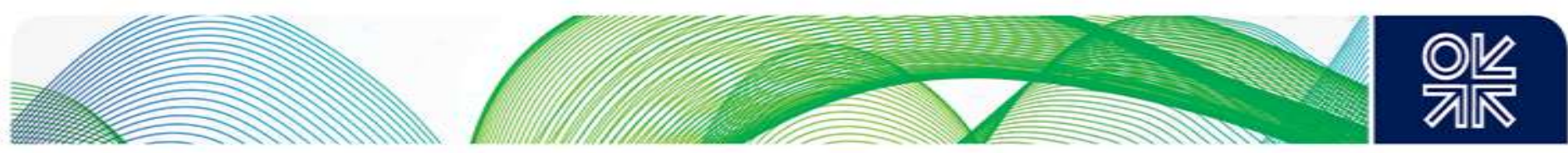

exporters can deliver their LNG worldwide and the destination of their cargos will depend substantially on prices paid by the different markets.

An option for international oil and gas companies (IOGCs) which tend to maintain gas reserve portfolios of less (and in most cases significantly less) than 20 years, would be to sell down those reserves and exit the methane business. But, similar to the points made above regarding the value of their European businesses to these companies, it is questionable whether IOGCs could recreate the scale of their natural gas business in the zero carbon energy space. The business model of IOGCs, honed over many decades, has been to discover and produce large volumes of (oil and) gas under long-term agreements, with the intention of selling it in large quantities over long periods of time (underpinned by long-term contracts). Non-fossil energy business models require significantly different skills and mindsets - particularly smaller decentralised projects - in contrast to the traditional model of large volume sales to national or regional suppliers, and (almost certainly) substantially lower returns. Reforming of methane combined with storage of carbon dioxide - probably in depleted fields owned by gas producers and transported through pipelines which may already exist or can be connected to those fields - requires modification of gas molecules and additional costs, but not fundamental changes to the existing business model. This logic suggests that the options for methane producers and exporters post-2030 are either reforming with CCS or progressively exiting Europe.

\section{Transmission and Distribution Network Owners}

\section{Past, present, and future}

In comparison with other sectors in the value chain, network companies were relatively protected from the immediate impacts of liberalisation. Most TSOs were demerged from merchant transmission companies with long-term ship or pay contracts (held by newly-created supply companies) and a regulated rate of return on their assets. This made them attractive investment targets for a new class of infrastructure investor seeking a moderate but guaranteed (regulated) rate of return. In the late 2010s, with long-term ship or pay contracts replaced by auction-based capacity bookings, the position of networks looks much more difficult as shippers are much less willing to make long-term commitments, preferring to book 'just in time' capacity which they are sure they will be able to utilise, and which will probably be increasingly available in an era of declining demand.

Beyond 2030, decarbonisation could become much more serious for networks than for producers. With their entire business model and the value of their assets dependent on methane being shipped through their pipelines on payment of a tariff, decarbonisation presents these companies with a potentially existential threat. As discussed above, decarbonisation of methane gas markets can be achieved via biogas, biomethane, synthetic methane (syngas), or hydrogen produced from a variety of feedstocks and processes. Networks need to be able to accept one, or a mixture, of these products, which may require anything from only marginal adjustments to complete replacement. This is where the distinction between transmission (high pressure, large capacity) and distribution (low pressure, usually urban) networks becomes crucial. Particularly because it is not only networks which may need to be converted to transport a different product, but customers whose appliances may need to be converted to use that product, and this is why choices made by distribution system owners and operators (DSOs) will be crucial, as some of these choices could result in these networks disconnecting from transmission networks. ${ }^{39}$ The potential for networks in different countries - and different regions of the same country - to be transporting different types of gas has wider security of supply consequences (to which we return below).

\section{Short and longer-term network narratives}

Blending hydrogen and green gases into the methane stream can be a short-term strategy for networks, particularly since their storage capacity will be needed during any transition to

\footnotetext{
${ }^{39}$ For example the choice to switch or convert a distribution network to biogas, biomethane or hydrogen, while the TSO remains using a different product.
} 

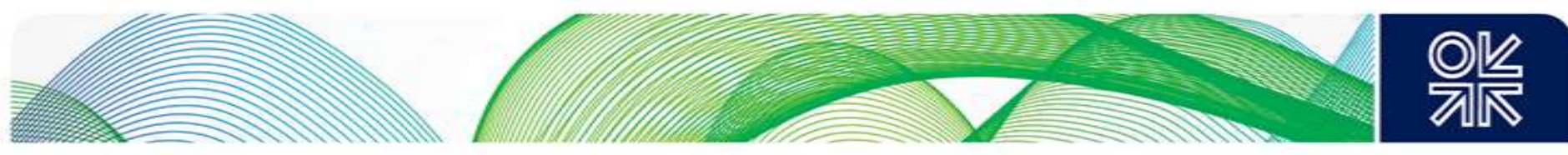

decarbonisation. ${ }^{40}$ But assuming accelerated decarbonisation in the 2030 s and beyond, the long-term narrative for networks must be transition to an alternative gas which logically could be biogas (for distribution networks), biomethane, bio SNG or hydrogen for transmission networks. As noted above, the most optimistic of the publicly available studies concludes there is potential to produce $98 \mathrm{bcm}$ of biomethane from biomass in EU countries by 2050, which represents only around 20 per cent of EU gas demand in the late 2010s. ${ }^{41}$ Therefore, a transition which would utilise the current capacity of gas networks would require very much larger volumes of decarbonised gas which would involve either substantial use of hydrogen or synthetic methane derived from a variety of sources. ${ }^{42}$

Any transition to hydrogen will require technical and infrastructural (pipeline replacement) change and therefore significant additional costs. As noted above, the two routes to decarbonised hydrogen are reforming of methane combined with CCS, and power to gas (electrolysis of water using renewable power). Pipeline transportation of hydrogen is limited and usage is mainly confined to the refinery and petrochemical industries; there is no experience of large scale conversion of residential/commercial customers to hydrogen. ${ }^{43}$ However, there is small scale experience of local hydrogen production and usage, by electrolysis of water using renewable power, and larger scale (100MW) power to gas projects are under development. Large-scale methane reforming projects for network distribution have been proposed, but we await the first billion-Euro investment which would confirm commercial scale technical and commercial viability. ${ }^{44}$

At a point when it becomes impossible to continue to utilise existing gas networks in decarbonised energy markets, tens of billions of investment value could become stranded which - even in private ownership - represents national assets. The future of gas networks is therefore very much a public policy - as well as an energy policy - decision. Transmission networks may be more vulnerable than distribution networks if the latter are able to adopt local solutions independent of the rest of the value chain. Any large-scale transition to hydrogen would require a new transmission network, but polyethylene distribution networks could be converted from methane to hydrogen without significant modification. ${ }^{45}$

To ensure that networks and customers are ready to undergo a transition to decarbonised gas in the 2030s, scaling up the full range of decarbonised gas projects must begin without delay in order to demonstrate the technical and logistical feasibility of the different options. Producers - whether of methane, biogas, biomethane, hydrogen or SNG - will need to be first movers in terms of decarbonisation commitments in order for networks to understand whether, and by when, their infrastructure will need to be adapted to receive a different product.

Many small scale biomethane and power to gas projects are already operating and others of larger scale are well advanced or in the planning stages, but the need to present a full range of convincing decarbonisation narratives is urgent. Ensuring that decarbonised feedstocks are available and that networks and (in the larger gas markets) millions of customers are ready to receive the decarbonised product (in whatever form) will require up to a decade to implement, and for hydrogen probably longer. (There are also cost and regulatory consequences of this gas decarbonisation transition which we address below.)

\footnotetext{
${ }^{40}$ See below for a discussion of the potential limits of hydrogen blending.

${ }^{41}$ Ecofys (2018).

42 See ADEME (2018) for a study which concludes that France could become completely independent of fossil gas by 2050.

This assumes that gas demand in France (excluding power generation) will be 34 per cent lower in 2050 than 2015.

${ }^{43}$ There are $4500 \mathrm{~km}$ of hydrogen pipelines around the world, half of which are in the US. Belgium has the longest hydrogen network in Europe at $613 \mathrm{~km}$. https://hydrogeneurope.eu/hydrogen-transport-distribution\#PIPELINES

${ }^{44}$ For examples from a range of countries see Hennig (2018). The European Power to Gas Platform

http://europeanpowertogas.com/ has an interactive map of P2G projects at various stages of development throughout Europe;

the vast majority are in Germany. For details of the UK projects see - H21 NOE (2018) and Hynet (2018).

${ }^{45}$ H21 NOE (2018) assumes that a new dedicated hydrogen transmission network would be built.
} 

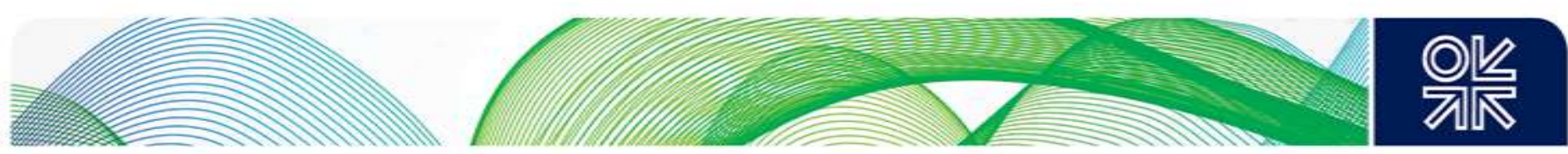

\section{Gas Suppliers}

Companies which supply gas to end-users are significantly less exposed to decarbonisation risks. In addition to gas, these companies (often referred to as 'utilities') are almost always supplying electricity and potentially other energy supply and demand management products to their customer base. Given that electricity is the main alternative to natural gas, these companies have the option of switching their customer base away from gas to power in the event either that electrification options prove more attractive, or that gas suppliers fail to decarbonise their product sufficiently rapidly. Lead times for changing the business model for the supply part of their business are much shorter than for other parts of the value chain, although these companies may also be owners of gas-related assets which would lead them to retain their gas supply business for at least the life of those assets.

\section{Storage, regasification, and gas-fired power asset owners}

The priority for owners of gas storages, LNG regasification terminals, and gas-fired power plants is to maximise the value of their assets until these either reach the end of their productive lives or cease to be profitable (potentially the same point in time). For power generators, asset life is considerably shorter (around 20 years) than for storages and regasification terminals (potentially 40-50 years) and therefore risks are correspondingly lower. For those planning to build new assets with a productive life stretching into the late 2030s and 2040s, there is an issue of whether these assets can be made 'decarbonisation-ready'. Any new investments in storage and regasification terminals should take into account the reality of decarbonisation well within their productive lives. It is unclear whether, and at what cost, methane storages could be converted to hydrogen. ${ }^{46}$ Regasification terminals would probably need methane reformers with $\mathrm{CO}_{2}$ capture to be integrated into the plants and pipelines connecting to offshore $\mathrm{CO}_{2}$ storage sites.

\section{Value chain cooperation and potential joint ventures}

The need for cooperation along the entire gas value chain, and the scale of finance to convert even a single region of several hundred thousand, - let alone several million (and in some countries, tens of millions of) customers, means that joint ventures or coalitions of networks (both transmission and distribution) and producers (and potentially also suppliers) will be necessary to implement such projects. Examples of relationships which have to be established and approved by regulators in order to establish decarbonised value chains, will be between existing networks and:

- biogas and biomethane producers;

- current methane producers;

- hydrogen producers - there are a range of possibilities depending on whether this product will be produced from:

- biomethane which would involve the producers of that product;

- renewable power which would involve the generators of that power and/or the networks involved in its transportation;

- steam/auto reformed methane which would involve methane producers (including pipeline and LNG exporters), existing TSOs, and owners of regasification terminals.

Targets will need to be agreed on the scale and timing of moving from unabated methane to a decarbonised product initially by means of blending, but with commitments to eventual full decarbonisation. These options will all require long-term commitments between gas and power value chain players - producers/generators, network owners, and owners of related assets - of a type which will not be possible in the current unbundled utility model. The required degree of change is likely to amount to a regulatory revolution.

\footnotetext{
${ }^{46}$ The German gas company VNG has a project to convert an existing methane gas storage facility to hydrogen storage.
} 

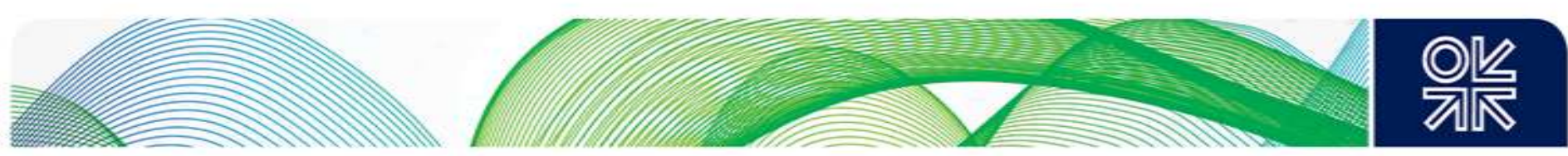

\section{A regulatory revolution: changing the focus from competition to decarbonisation}

The cornerstone and ultimate priority of the EU liberalisation experiment which has been ongoing for several decades through several EU energy 'packages' has been the unbundling of networks, allowing access for all potential users in order to create competition, promote efficiency, and reduce prices for consumers. The future is almost certainly going to require agreement that decarbonisation is the absolute priority of future energy regulation, and competition will need to be subordinated to that goal. To some extent this has already happened in the electricity sector where governments (either directly or via regulation) have provided financial support to promote zero carbon renewables (and in the UK, nuclear power), albeit with competitive elements such as auctions. But large-scale gas decarbonisation will require much greater changes in relation to allowing cooperation between producers and networks and suspending competition requirements, at least in the early stages of the process. It is likely that this will be achieved by introducing targets for the percentage of decarbonised gas which must be transported by networks by specified future dates, similar to targets for renewables, efficiency, and overall carbon reduction.

In addition to the issue of cooperation and re-verticalisation ('rebundling') of the value chain, the question of cost recovery of conversion for gas networks (and potentially also storages) and allocation of costs of carbon storage and customer conversion will be extremely complex. These costs will differ depending on the route chosen for decarbonisation: biomethane, synthetic methane or hydrogen. There will be a number of different network choices - certainly for distribution networks but also for transmission networks - within one country (and potentially also within one region). Some of these choices may only require relatively minor adjustments to existing networks and customer equipment. However if a significant proportion of networks and customers need to be converted to hydrogen to retain the scale of the existing gas market, as suggested above, this will probably require significant new and dedicated transmission networks. ${ }^{47}$ Parts of transmission networks may be decommissioned -because they are no longer needed for regions which have chosen electrification options, and this needs to be recognised in relation to amortisation and cost recovery.

Alongside the economic regulatory issues, standards will need to be reviewed (and in some countries introduced) for the technical/safety aspects of biogas, biomethane, and hydrogen transportation; specifically, the percentage of those products which can safely be transported in the methane stream. This applies particularly to hydrogen, where the percentage allowed in European networks varies from 0-12 per cent. Literature on safe limits to hydrogen blending is contradictory but up to 20 per cent may be possible which would reduce $\mathrm{CO}_{2}$ emissions from gas by 7 per cent. ${ }^{48}$ Safety limits may depend on the age and quality of the steels used in existing pipelines, and TSOs will need to categorise their networks accordingly. This is particularly important since blending these gases into methane networks is the obvious starting point for decarbonisation. New legal and fiscal frameworks will need to be established for all decarbonised gas projects, particularly for large-scale hydrogen projects with CCS, because these will be highly capital-intensive.

Costs will need to be justified on the grounds of meeting carbon reduction targets and expressed in terms of avoided carbon emissions, with asset life and ongoing regulatory returns dependent on meeting targets for transitioning to decarbonised gas. A long-term regulatory framework will be needed to recover costs and enable financing of projects to proceed. A study commissioned by the

\footnotetext{
${ }^{47}$ Plastic (polyethylene) distribution networks require some changes to be converted to hydrogen, but high pressure transmission networks (unless constructed of very high grade steel) will need new dedicated networks. H21NOE, which deals with the transition of a large city and a substantial region to hydrogen assumes that the existing methane network will continue to operate until a new dedicated hydrogen network is in place.

${ }^{48}$ Current blending limits are 0.1 per cent in the UK, New Zealand, Belgium, and the US; 10 per cent in Germany and 12 per cent in the Netherlands. These percentages are by volume but hydrogen has only around one third of the energy content of methane. IEA (2018), p.507.
} 

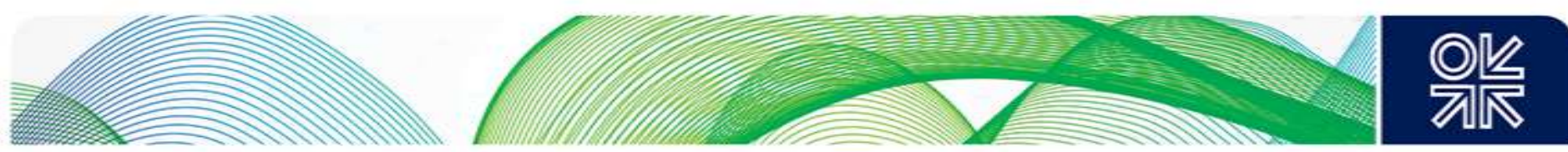

Council of European Energy Regulators reviewed these issues at a high level but seemed to underestimate the degree of regulatory and policy change which would be needed (follow-up studies are under way). ${ }^{49}$

A UK study of market models and regulatory frameworks for a low carbon gas network in 2050 concluded that: 50

$\therefore$...many aspects of the market and regulatory framework could remain similar to those in place today'...In High Hydrogen over 80 SMR plants compete with multiple electrolysis plants and imports on the production of hydrogen. In Methane Peaking hundreds of AD and syngas plants compete with imports...Even in Regional Gas Grids, where imports play a smaller role, and two separate markets exist for hydrogen and low carbon methane, the number and scale of plants on the production side in each market imply that competition would be possible'.

But even if such conditions can realistically be created by 2050 (which this author doubts), questions remain as to how competition could operate while this number of plants and regional gas grids were being developed, and whether this would be possible under anything resembling the current regulatory framework. ${ }^{51}$

\footnotetext{
${ }^{49}$ CEER (2018a) and CEER (2018b).

${ }^{50}$ Frontier Economics (2018), p.131 High Hydrogen, Methane Peaking and Regional Gas Grids are the three scenarios considered in the study.

${ }^{51}$ Some of these issues are addressed in bullet point form in Amhilat (2018).
} 

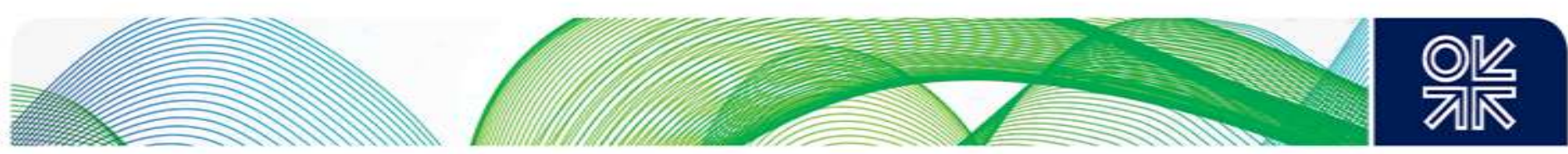

\section{Uncertainties: time frames and costs}

\section{Time frames}

In countries where government policy dictates that the power sector must be largely decarbonised by 2030 , followed by the heat sector in the two subsequent decades, the time available to demonstrate whether methane can be retained in the energy balance on a large scale beyond the next 20 years is relatively short. Following this logic, certainly by the mid-2020s - and arguably already - it will no longer be possible to sign contracts for methane exceeding 15 years (and even this duration may be difficult) unless it can be demonstrated that methane decarbonisation arrangements will be in place by the end of that period. Similar logic suggests that it will not be possible to recover methane-related infrastructure investments requiring a longer depreciation period. Therefore, the necessity to demonstrate that the different decarbonised gas options are realistic and cost-effective against alternative low/zero carbon options is urgent, in order to provide sufficient time for a large-scale gas network transition over the following 25 years up to 2050. This means that the pilot projects currently in operation will need to be followed relatively quickly by commercial scale projects in order to be operational by 2025; this in turn will require the technical, regulatory, and financial frameworks to be in place to allow final investment decisions to be taken in the early 2020 s.

In summary, assuming governments in the major European gas markets are committed to meeting COP21 targets, gas stakeholders - and especially gas networks - do not have another 10 years to continue to discuss and debate their future. Investments in the first commercial scale projects need to be rolled out by the mid-2020s to demonstrate successful large scale technical and commercial viability which could provide gas networks with life extension beyond the 2040s. For these reasons there are major uncertainties (mentioned above) that need to be addressed in the next several years, of which the most immediate are technical and logistical difficulties and costs. In particular, establishing the limits of blending hydrogen into the methane stream will be an important first step towards decarbonisation.

\section{Costs}

It is extremely difficult to make accurate cost estimates for the different decarbonisation options. Figure 6 shows a wide range of cost estimates for renewable gases. Only those for biogas come close to 2018 European hub prices which ranged from $€ 19-28 / \mathrm{MWh}{ }^{52}$ The low estimates of biomethane, power to hydrogen and particularly power to methane costs range from $€ 40-80 / \mathrm{MWh}$ while the high estimates are $€ 150-260 / M W h$. Following the example of renewable energy costs, it can be hypothesised that these costs will fall as the number and scale of projects increases, and that is why it is essential for the gas community to launch commercial scale projects as soon as possible. But, as noted above, due to the fact that these projects will require investments of hundreds of millions, probably billions of Euros, and that currently there is no business case for such investments in terms of a commercial rate of return, financing and rates of return must - at least initially - be part of a new regulatory framework. 

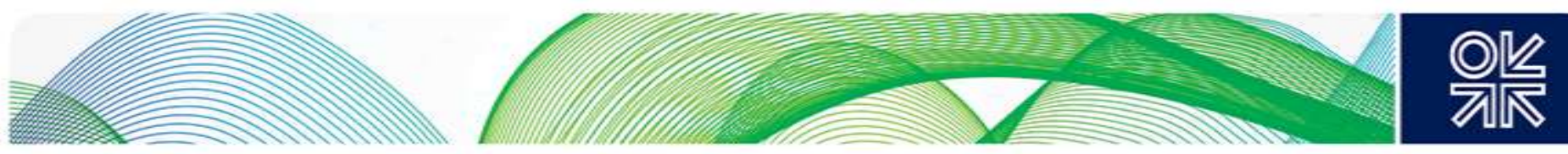

Figure 7: Range of Cost Estimates for Renewable Gases

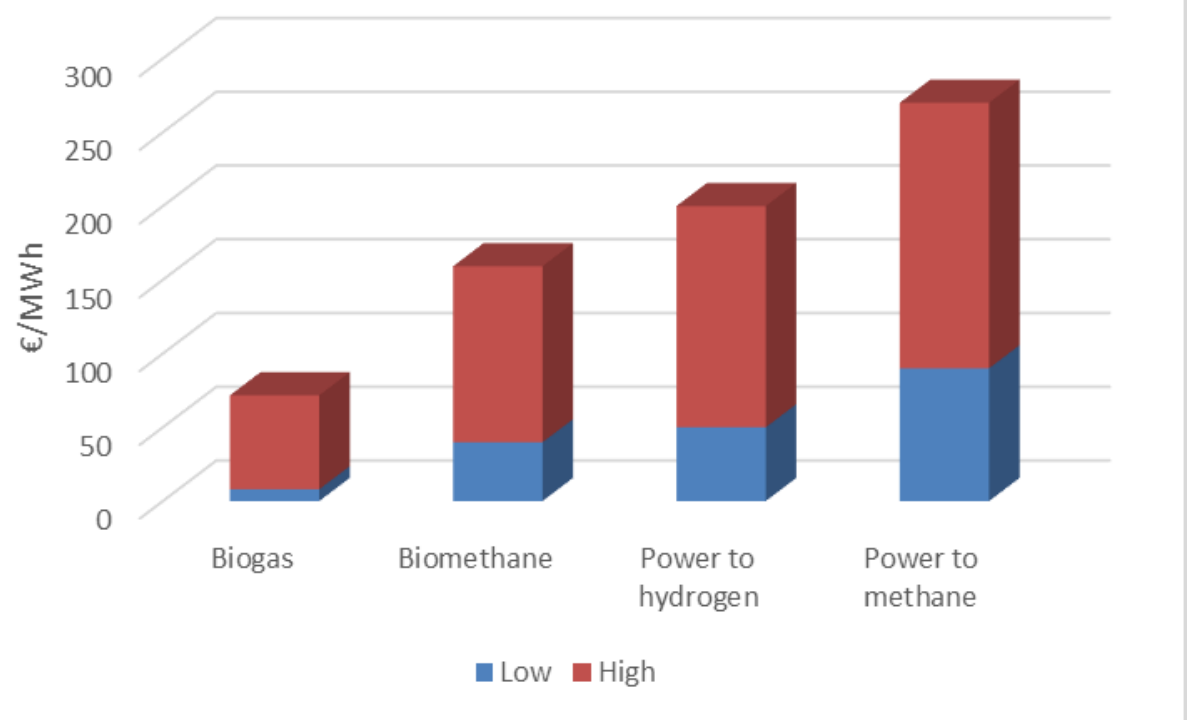

Source: Lambert (2018b).

Attempts to compare the costs of hydrogen from electrolysis with steam reformed methane (SMR) and coal gasification will tend to be location-specific. An estimate of Australian costs shows off-grid electrolysis to be slightly more expensive but 2-3 times higher than the reforming/gasification route for curtailed or grid-based power. ${ }^{53} \mathrm{~A}$ different study found that the costs of electrolysis were nearly four times that of SMR plus CCS, and that electrolysis would not become cost-competitive until around $2040 .{ }^{54}$ 

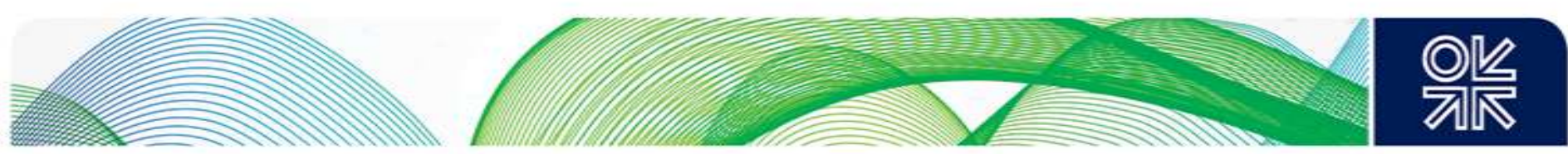

\section{Threats to Decarbonised Gas Narratives}

There is no guarantee that the decarbonised gas narratives set out in this paper will be sufficiently convincing to be successful in the majority of EU countries. This section sets out the likely principal threats to these narratives.

\section{Security threats}

\section{Geopolitics and dependence on Russia}

A short-term risk to methane-based narratives (unrelated to decarbonisation) is increasing European dependence on Russian gas, in the context of a sharp decline in European domestic production, which is ongoing at the end of the 2010s. Based on preliminary 2018 data, Russian gas exports to Europe had increased by nearly 30 per cent since 2014 when the annexation of Crimea and military activity in eastern Ukraine plunged Russia-EU political relations to post-Cold War lows. ${ }^{55}$ Since then Russian gas exports have been curtailed and new pipelines threatened with delay and cancellation by a series of EU political and parliamentary initiatives and energy and competition proceedings, but these have not been sufficient to counteract the market forces which have drawn increasing Russian volumes into Europe. ${ }^{56}$ The principal reasons for this have been: a precipitous fall in Dutch gas production and exports; a lack of substantial alternative pipeline supplies; strong LNG demand in Asia with prices above European hubs; and a strong recovery of European gas demand post-2014. ${ }^{57}$ Under currently anticipated supply/demand conditions, the projection by Gazprom's marketing department that the company could have a market share of 40 per cent or more by the 2030s (compared with 34 per cent in 2017) could be achieved more rapidly. ${ }^{58}$

A negative reaction to this level of dependence by European governments (and the European Commission) if political relationships with the Russian Federation fail to improve and certainly if they deteriorate further, would impact the judgement (noted in the Introduction as a conclusion from previous work) that the 2020 s could be an extremely positive decade for gas suppliers. Geopolitical concerns related to over-dependence on Russian gas could - for some gas markets and conceivably for Europe as a whole - combine with climate change considerations to jeopardise the post-2030 future of natural gas on political and security grounds. Any major disruption of Russian supplies to Europe post-2019, following the termination of the Ukrainian transit contract, would add to such concerns. $^{59}$

\section{Fragmentation of unified networks carrying a homogeneous product}

In the traditional gas industry, suppliers provided, and networks transported, unabated methane to all customers. Debates about security of supply focus on whether sources of supply are sufficiently diversified, with the aim of avoiding undue dependence on a single supplier, and whether they are robust against technical or political interruptions. As gas industries decarbonise, the paradigm of all networks within a single country, and across the EU as a whole, using a homogeneous methane product will gradually transform into a patchwork of networks carrying different gases including hydrogen. ${ }^{60}$ This will substantially impact the single European gas market and could make redundant

\footnotetext{
55 Exports to Europe in 2018 have been quoted as 201 bcm (Russian units); data for previous years and projections to 2030 can be found in Pirani (2018a), pp.11-13.

${ }^{56}$ For details of these EU judgements and proceedings concerning the OPAL pipeline, Nord Stream 2, and the DG COMP case against Gazprom, see: Yafimava (2018), Yafimava (2017a), Yafimava (2017b), Stern and Yafimava (2017).

${ }^{57}$ For details of these developments see: Honoré (2017), Pirani (2018b), Rogers (2017), Honoré (2018).

58 Henderson and Sharples (2018).

59 Pirani (2018a).

60 The decades-long division of north-west European gas networks between low-cal (Groningen) and high-cal gas is being phased out with the closure of the Groningen field by (and probably before) 2030 .
} 

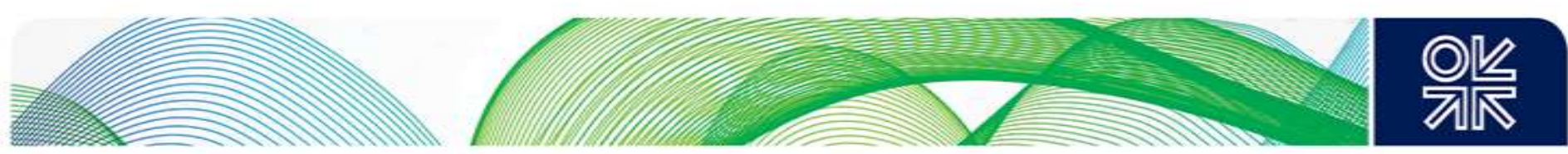

many of the pipeline interconnections between countries which have been (and continue to be) established.

A transition to national (and regional) networks carrying different products would significantly impact the security of supply regulations in place as, in the case of a supply shortage, it would disrupt the solidarity principles governing sharing of available gas between countries and regions. ${ }^{61}$ This would emphasise the advantages of a transition to synthetic methane of a defined calorific value - derived from biomethane and hydrogen - rather than different gases. It would also remove the necessity to convert existing networks and customers to a different non-methane product. However, these advantages would be counter-balanced - and potentially outweighed - by the increased costs and loss of efficiency from conversion processes.

\section{Climate policy and methane leakage}

The gas narratives which have been advanced here contain significant elements which will not be accepted by some policymakers and many in the non-fossil fuel community. At one extreme are what might be called 'hydrocarbon rejectionists', for whom any suggestion that natural gas use will be prolonged in any form and for any reason is unacceptable. ${ }^{62} \mathrm{~A}$ less extreme form of hydrocarbon rejection can be found in modelling exercises which make assumptions on the speed of phasing out all fossil fuels from European (and global) energy balances. ${ }^{63}$

An important aspect of the producer narrative will be measures to reduce fugitive emissions of methane from the gas chain. Previous research discussed this subject, ${ }^{64}$ and since then BP and Shell have committed to limit emissions to $0.2-0.3$ per cent of gas extracted and transported by the mid2020s. ${ }^{65}$ Increasing numbers of companies have joined the various industry initiatives to reduce fugitive methane, including $\mathrm{OGCl}$, Methane Guiding Principles, Oil and Gas Methane Partnership, and ONE Future. ${ }^{66}$ As previous papers observed, common methane targets, standards, and measurement are taking a very long time to put in place. Establishing transparent methodologies to demonstrate delivery of these metrics will be an important part of the producer narrative. ${ }^{67}$

For these reasons, it cannot be assumed that narratives which extend the timescale of unabated methane will be accepted. Parts of these narratives in relation to biogas, biomethane, and power to gas, may be accepted, but other parts, for example reforming of methane to produce hydrogen, may be rejected either because of antipathy to hydrocarbons or because of a lack of suitable carbon storage structures, or because other decarbonisation routes will be lower cost and/or more politically acceptable.

\footnotetext{
${ }^{61}$ Security of Supply Regulation 2017: 'Regulation (EU) 2017/1938 of the European Parliament and of the Council of 25 October 2017 concerning measures to safeguard the security of gas supply and repealing Regulation (EU) No 994/2010', OJ L 280/1. For commentary on this Regulation see Yafimava (2018), 131-6.

${ }^{62}$ For example, Anderson and Broderick (2017), p.5. who conclude: `Fossil fuels (including natural gas) have no substantial role in an EU 2 degrees $C$ energy system beyond 2035. Consequently within two decades, fossil fuel use including gas, must have all but ceased, with complete decarbonisation following soon after'. For modelling results from the UK see McGlade et al. (2014).

${ }^{63}$ The principal assumption being that carbon reduction must (and therefore will) happen over a specific time scale. For a review of some of these studies see Stern (2017b), pp. 6-9.

${ }^{64}$ Stern (2017b), 29-30 and Appendix 4; Le Fevre (2017).

${ }^{65}$ Methane Matters: the science and the challenges, 27 June 2018 https://www.bp.com/en/global/corporate/bpmagazine/observations/managing-methane-emissions-from-gas-production.html; Shell announces methane emissions intensity target for oil and gas assets, September 17, 2018, https://www.shell.com/media/news-and-media-releases/2018/shellannounces-methane-emissions-intensity-target.html

${ }^{66}$ Oil and Gas Climate Initiative (OGCI), http://oilandgasclimateinitiative.com/; Methane Guiding Principles http://ccacoalition.org/en/resources/reducing-methane-emissions-across-natural-gas-value-chain-guiding-principles; ONE Future, http://onefuture.us/ See also Climate and Clean Air Coalition, (2017).

${ }^{67}$ For some updated data on methane emissions and observations on comparing emissions from coal and gas, see Appendix A.
} 

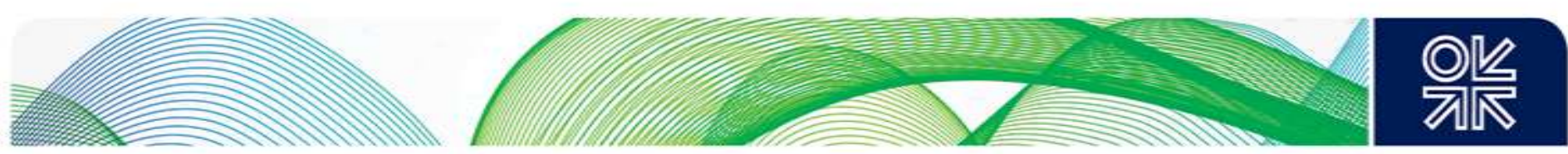

It is possible that governments may opt for electrification options even if these involve higher costs and the stranding of substantial gas network assets. But in any event ongoing electrification suggests lower utilisation of these assets. It may also be that governments will appear to accept these narratives but fail to implement the regulation and carbon taxation/pricing which will be required to ensure that decarbonised gas projects progress. In which case, the gas industry will carry on largely unchanged with the most likely outcomes being that gas will progressively be replaced by electrification, otherwise carbon targets will not be met.

\section{Commercial and regulatory threats - particularly for gas networks}

The most serious commercial threat to private, investor-owned companies is the ability to develop and credibly deliver a decarbonisation narrative given the short time horizons which shareholders require for financial returns. In this commercial environment, it is very difficult to discuss the need for time, attention, and investment to be devoted to a post-2030 (let alone a 2050) world. But as noted above, decarbonisation presents an existential threat particularly for existing gas networks. One result of the logic (outlined earlier) that decarbonisation targets will require competition to be downgraded as a regulatory priority may be increasing state (or municipal) ownership of networks, in cases where these need to be replaced, or newly built. An alternative would be a franchise monopoly for investors in new infrastructure with guaranteed regulatory returns over a long period of time.

One of the most controversial propositions of this narrative for governments and regulators will be that, although there will be competition in relation to project selection, gas-to-gas competition will almost certainly not operate in the initial stages of establishing a decarbonised gas market. For many years there will be too few sources of biomethane and hydrogen to create a fully competitive market. A major task will be to reintegrate a fragmented value chain in order to launch such projects. There will be little point in producing hydrogen unless networks and customers are ready to receive it, and this will require substantial cooperation and coordination between all parties. This problem lends itself to speculation as to whether hydrogen networks will need to be in state ownership to justify the costs, and if policy makers reject that option whether hydrogen will be rejected as a source of decarbonised gas due to what Keay has called 'the wrong sort of technology and the wrong sort of economics'. ${ }^{6}$

\footnotetext{
${ }^{68}$ Keay (2018) referring specifically to the UK.
} 

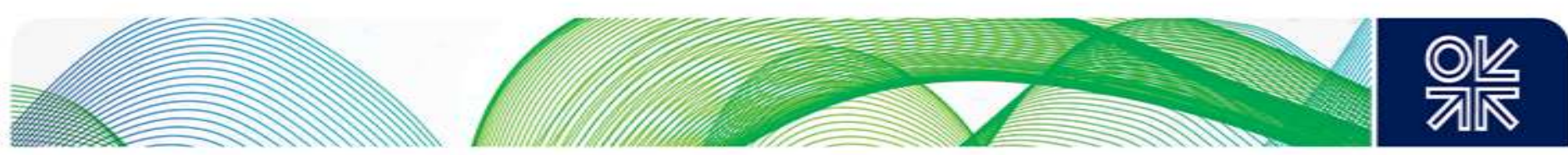

\section{Summary and Conclusions}

This paper is premised on the assumption that the major EU gas markets where governments are committed to decarbonisation ${ }^{69}$ will follow through on their carbon reduction commitments under COP21. Even if doubts about that assumption arise, it would be extremely risky for the natural gas community to assume that governments will decide to drastically delay or abandon those commitments. The advocacy narrative of the gas community which focused on coal to gas switching and backing up renewables, while logical, failed to convince governments, NGOs, and media commentators that it can help achieve post-2030 decarbonisation targets. The gas community therefore needs to develop decarbonisation narratives which address the post-2030 period, the components of which are:

- the size and timing of developing commercial scale projects for biogas, biomethane, and hydrogen (from both power to gas and reformed methane). Current studies suggest that the maximum availability of biomethane and hydrogen from power to gas would be equivalent to 25 per cent of European gas demand at the levels of the late 2010s;

- therefore, large scale hydrogen production from reforming methane with carbon capture, utilisation and storage (CCUS) will be needed to maintain anything close to current demand levels. Neither of these technologies is well-developed on a large scale, and aside from its use in enhanced oil recovery, CCUS is not commercially viable;

- the requirements for developing decarbonised gas projects in terms of technical regulation, legal and fiscal frameworks, and government support either in terms of a carbon price/tax or direct project support. However, the gas community needs to be clear that very substantial corporate investment needs to be part of its narrative, rather than relying only on government funding or regulatory support.

A very important theme of this paper is that the choices which national governments, regional and municipal authorities, and companies will make - and the criteria which they will employ to make them - will differ within, as well as between, countries. This is likely to mean that the paradigm of gas markets transporting a homogenous product through a unified network will change significantly post2030 as different choices result in different products which, in the case of hydrogen, will require new transmission (but not necessarily distribution) networks.

These developments will have different impacts on the different parts of the value chain. Pipeline gas suppliers will need to progressively decarbonise their product if it is to remain saleable. LNG suppliers have the option of abandoning European markets in favour of those importing regions where decarbonisation policies have yet to have a major impact. However, networks face a potentially existential threat unless they can maintain existing throughput while adapting to a decarbonised product, or their regulatory frameworks are adjusted to maintain profitability at much lower throughput levels.

Significant threats and challenges to these narratives are already visible. These include:

- short term geopolitical concerns stemming from dependence on Russian gas, "hydrocarbon rejectionism', and the inability of companies to plan and invest for a post-2030 decarbonised future;

- value chain fragmentation and longer term inability to persuade governments and regulators to create regulatory frameworks, amounting to a 'regulatory revolution', which will be needed to create a business case for large scale gas decarbonisation projects.

\footnotetext{
${ }^{69}$ These markets are: Germany, Netherlands, Belgium, France, Italy, Spain, and the UK. These markets accounted for more than 75 per cent of EU gas demand in the late 2010s.
} 

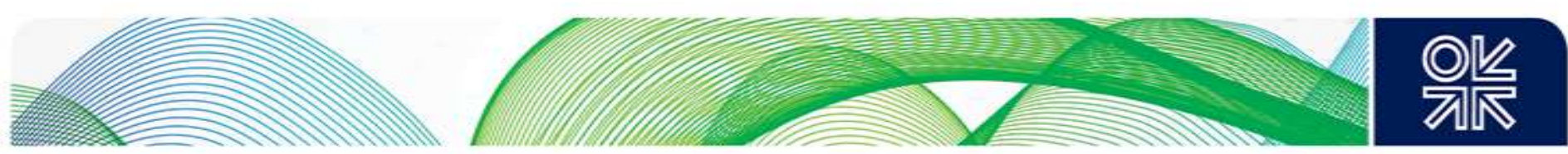

While decarbonised gas narratives have no guarantee of success, failure to construct them and be prepared to back them up with investments means that, in countries where carbon reduction targets remain a policy priority which will be enforced, the future of methane supply and infrastructure post2030, and especially post-2040, will become progressively limited. Narratives will need to include commitments which will form the basis of corporate strategies, with urgency to demonstrate these are being acted upon. If the EU gas community fails to advance convincing decarbonised narratives and/or governments fail to create the necessary legal/fiscal and regulatory frameworks, then energy markets will progressively move in the direction of electrification. The next 5-10 years will be a crucial period for the gas community to put forward, and demonstrate how it will deliver, credible decarbonisation narratives.

\section{Non-EU Gas Narratives}

This paper specifically addresses decarbonisation in the major EU gas markets where governments have strongly carbon-centric energy policies. It could also be applied more widely in Europe, and in any country or region where governments have accepted, and shown determination to implement, deep cuts in carbon emissions. Examples would be Japan and individual US states (such as California), with similar carbon-reduction ambitions and the financial and regulatory capacity to implement them. However, as previously observed (Stern 2017b), government policy in the major European gas markets is more climate-centric than in other European countries, and much more than in non-OECD regions where climate change is much lower down the policy agenda than air quality, energy affordability, and security (usually defined as dependence on imports).

In these countries and regions, in contrast to its reception in major European gas markets, the gas advocacy narrative - in particular coal to gas (and in some regions oil to gas) switching and support for renewables - is likely to be viewed as a credible carbon reduction policy. This could be particularly effective when combined with the need to rapidly improve urban air quality. China is the obvious example where this has been successful, but it could also gain traction in other Asian countries with similar problems. In these countries, and elsewhere in the non-OECD world, the adoption of a fuelswitching narrative may depend crucially on the affordability of (particularly) imported LNG in comparison to domestic (and even imported) coal and renewables. High gas, particularly LNG, import prices will make this impossible and will favour a prolongation of coal use and/or a switch to renewables. 

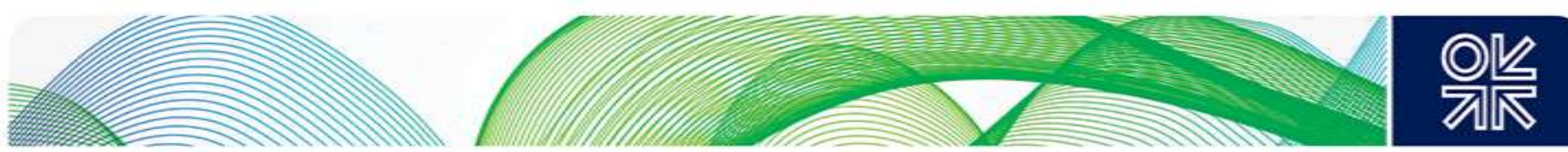

\section{APPENDIX A: Methane Emissions: data and methodology}

There is a considerable literature on methane leakage, much of which was reviewed in a previous publication by the author. ${ }^{70}$ This appendix updates the public domain estimates of the IEA and emphasises the importance - and the difficulty - of precise statistical collection of data for any specific comparisons of emissions between fuels and countries.

Figure A1: Breakdown of GHG emissions by element for oil and gas, 2017
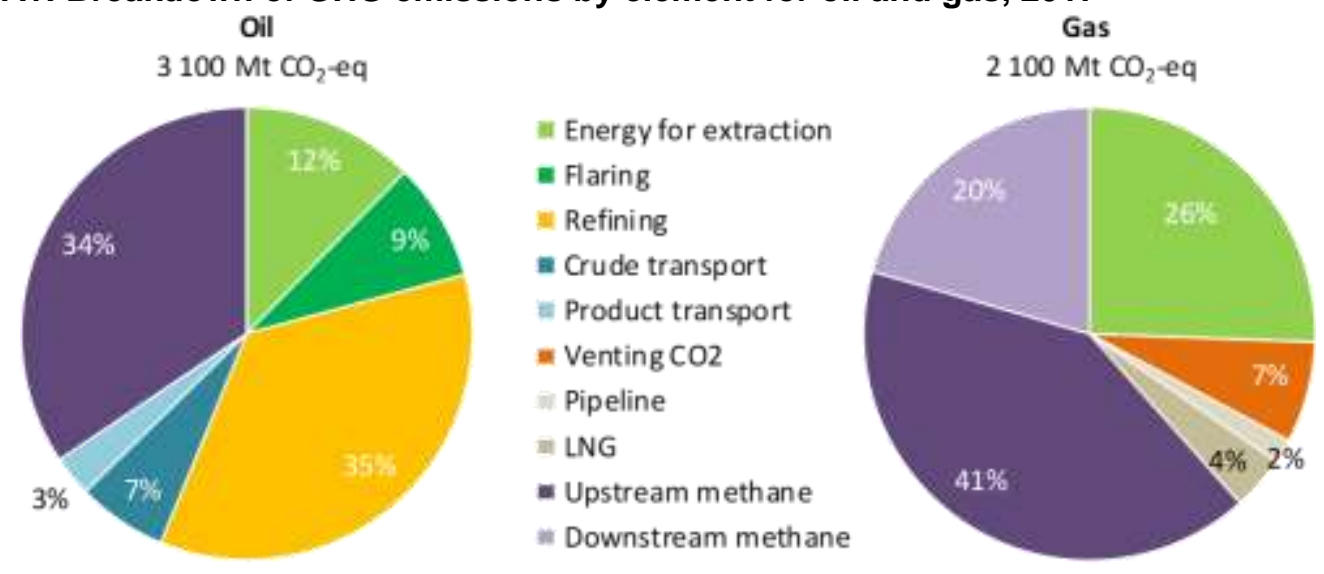

Source: IEA (2018), Figure 11.8, p.491.

Figure $\mathrm{A} 1$ shows the breakdown of the $36 \mathrm{mt}$ of methane emissions from oil production and processing, and $43 \mathrm{mt}$ from production, processing and transport of natural gas. ${ }^{71}$ The IEA has estimated that 45 per cent of the $79 \mathrm{mt}$ of total oil and gas emissions could be avoided at no net cost to the industries (at 2017 gas prices). ${ }^{72}$

Comparing lifecycle emissions intensities of gas and coal in the production of electricity, the IEA estimates that: ${ }^{73}$

- Using the 100-year global warming potential (1 tonne of methane $=30$ tonnes of $\mathrm{CO}_{2}$ equivalent), 99.7 per cent of gas produced and consumed in 2017 is cleaner than coal when producing electricity. Electricity produced from gas transported as LNG results on average in 45 per cent fewer GHG emissions than coal.

- Using the 20-year global warming potential (1 tonne of methane $=85$ tonnes of $\mathrm{CO}_{2}$ equivalent), over 97 per cent of gas produced in 2017 would still be cleaner than coal.

However, although providing comparisons on a global basis means averaging is inevitable, comparisons of gas versus coal emissions require specific data for each source. For example, an exercise which seeks to compare the emissions of gas from a certain source with emissions from coal which this gas would replace must estimate:

- the methane and $\mathrm{CO}_{2}$ emissions from the gas delivery chain including: the specific field, pipeline, LNG liquefaction, and regasification facilities from and through which the gas is delivered and compare this data with.

\footnotetext{
${ }^{70}$ Stern (2017b), Appendix 4.

71 IEA (2018), p.493.

72 Ibid, Figure 11.10, p.494.

${ }^{73}$ lbid, Box 11.3, p.490.
} 

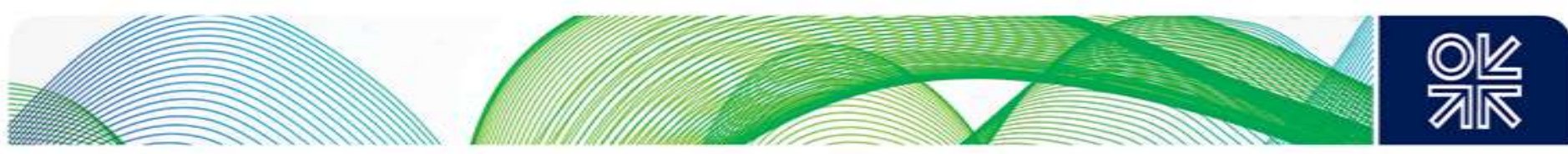

- the $\mathrm{CO}_{2}$ and methane ${ }^{74}$ emissions from the specific coal mine, coal transportation, and handling facilities of the existing coal supply.

This is a difficult empirical data collection and analysis exercise, but failure to carry it out risks simply using generalised data from different sources carrying with it suspicions that the aim is to 'prove' that one fuel has lower emissions than the other.

The overall aims of the gas community in relation to methane emissions should be the collection of data (and explanation of the methodology behind this data collection) to enable:

- analysis of methane and $\mathrm{CO}_{2}$ emissions data from gas industry operations on a national basis. At present, companies are collecting data on a corporate basis, specifically emissions from their own operations, whereas the emphasis needs to be increasingly on obtaining estimates of gas industry emissions from national gas chains

- analysis of methane and $\mathrm{CO}_{2}$ emissions data from gas pipeline and LNG imports from the producing field to the border of the importing country.

\footnotetext{
${ }^{74}$ The reason for emphasising methane emissions from coal is that very often studies only compare the $\mathrm{CO}_{2}$ emissions from coal with $\mathrm{CO}_{2}$ and methane emissions from gas. This neglects the fact that global methane emissions from coal are only slightly lower than those from gas - 43mt for gas compared with 40mt for coal in 2015 (IEA 2017, pp. 416-7) - and therefore methane and $\mathrm{CO}_{2}$ from both sources need to be taken into account when comparing the emission values from both fuels.
} 


\section{BIBLIOGRAPHY}

ADEME (2018): A 100\% Renewable Gas Mix in 2050?

https://www.ademe.fr/sites/default/files/assets/documents/renewable-gas-mix-2050-010521.pdf

Amilhat, J. (2018): 'Gas Infrastructure 2050 Study', presentation to the Madrid Forum, October 16, 2018.

Anderson, K. and Broderick, J. (2017), Natural Gas and Climate Change, Tyndall Manchester, Cemus and Teesside University, 17 October 2017.

www.foeeurope.org/sites/default/files/extractive industries/2017/natural gas and climate change a nderson broderick october2017.pdf

Bogle, S. (2018), 'Aussie LNG sector targets blue hydrogen potential', Interfax Natural Gas Insight, January 24, 2019, p.7.

Bowden, J. 'EC hatches plan to cut carbon', Natural Gas World, Vol 4, Issue 2, January 21, 2019, pp. 10-11.

BP Energy Outlook 2018 Edition. www.bp.com/en/global/corporate/energy-economics/energyoutlook/energy-outlook-downloads.html

Braaksma, A. 'A study of scenarios to 2050 using Primes', presentation to the Madrid Forum, October 16, 2018.

CCS Institute, The Global Status of CCS 2018, https://adobeindd.com/view/publications/2dab1be7edd0-447d-b020-06242ea2cf3b/qhaw/publication-webresources/pdf/CCS Global Status Report 2018 Interactive.pdf

CEER (2018a), Study on the Future Role of Gas from a Regulatory Perspective, 6 March, 2018. https://www.ceer.eu/documents/104400/-/-/6a6c72de-225a-b350-e30a-dd12bdf22378

CEER (2018b), CEER Follow-up to the 'Study on the Future Role of Gas from a Regulatory Perspective', presentation to the Madrid Forum, October 16, 2018.

CEN (2018): 'Standardisation with regard to renewable gases and hydrogen blending', presentation to the Madrid Forum, October 1617, 2018.

CERRE (2018), Gas and the Electrification of Heating and Transport: scenarios for 2050, March 2018, https://www.cerre.eu/publications/gas-and-electrification-heating-transport-scenarios-2050

Corporate Europe Observatory (2017), The Great Gas Lock-in: industry lobbying behind the EU push for new gas infrastructure,

https://corporateeurope.org/sites/default/files/the great gas lock in english .pdf

Climate and Clean Air Coalition (2017), Oil and Gas Methane Partnership (2017), $2^{\text {nd }}$ year Report. http://www.ccacoalition.org/en/resources/oil-and-gas-methane-partnership-ogmp-second-year-report

Chiyoda (2018): 'SPERA Hydrogen', paper delivered to the Hydrogen Energy Ministerial Meeting, Tokyo, October 2018. https://www.nedo.go.jp/english/ZZHY 00002.html

DNV GL, 'Energy Transition Outlook: the role of gas in a greener Europe', 19th European Gas Conference, 29-30 May, Oslo 2018.

Ecofys (2018): Gas for Climate - how gas can help to achieve the Paris Agreement target in an affordable way, February 2018.

https://www.gasforclimate2050.eu/files/files/Ecofys Gas for Climate Report Study March18.pdf 

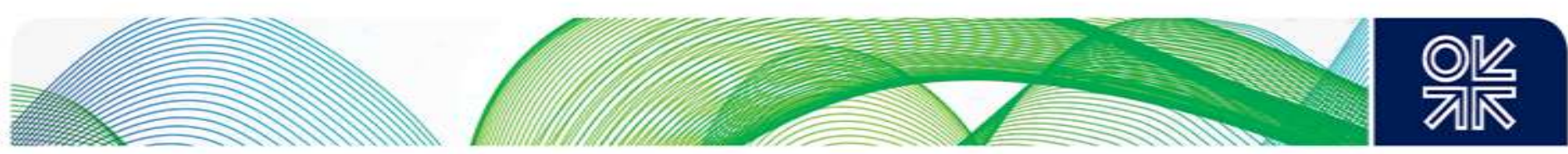

Element Energy (2018): Cost analysis of future heat infrastructure options, https://www.nic.org.uk/wpcontent/uploads/Element-Energy-and-E4techCost-analysis-of-future-heat-infrastructure-Final.pdf

Entsog/TYNDP (2018), Annex II, Methodology, Scenario Report.

https://entsog.eu/sites/default/files/entsog-

migration/publications/TYNDP/2018/entsos tyndp 2018 Final Scenario Report ANNEX II Method ology.pdf

Equinor, Energy Perspectives 2018, https://www.equinor.com/en/how-and-why/sustainability/energyperspectives.html

Equinor (2017): 'Evaluating conversion of natural gas to hydrogen', July 7, 2017.

https://www.equinor.com/en/news/evaluating-conversion-natural-gas-hydrogen.html

European Power to Gas Platform (2017): Power to Gas in a Decarbonised European Energy System Based on Renewable Energy Resources, White Paper.

http://www.europeanpowertogas.com/media/files/European\%20Power\%20to\%20Gas White\%20Pap er.pdf

Fincke, J.R., Anderson, R.P., Hyde, T.A. and Detering, B.A. `Plasma Pyrolysis of Methane to Hydrogen and Carbon Black', Industrial Energy Chemical Research, Vol 41, 2002, pp.1425-1435.

Fischer, L. Renewable and Decarbonised Gas: options for a zero emissions society, E3G, June 2018. https://www.e3g.org/library/renewable-and-decarbonised-gas-options-for-a-zero-emissions-society

Florence School of Regulation (2018), 'All you need to know on the EU energy market in 2018$2019 \ldots$ in one interview!', http://fsr.eui.eu/need-know-eu-energy-market-2018-2019-one-interview/ January 19, 2018.

Florence School of Regulation (2019), `Exclusive Interview with Borchardt (EC)! From Madrid Forum to the Gas Package', http://fsr.eui.eu/exclusive-interview-with-borchardt-ec-from-madrid-forum-to-thegas-package/ January 9, 2019.

Friends of the Earth Europe: Can the climate afford Europe's gas addiction? November 2017. https://www.foeeurope.org/sites/default/files/extractive industries/2017/can the climate afford europ es gas addiction report november2017.pdf

Frontier Economics, Market and Regulatory Frameworks For a Low Carbon Gas System, A report for BEIS, March 2018.

https://assets.publishing.service.gov.uk/government/uploads/system/uploads/attachment data/file/69 9678/Final BEIS low carbon gas 070318 clean-STC.pdf

H21 NOE (2018): H21 North of England, November 2018.

https://www.northerngasnetworks.co.uk/h21-noe/H21-NoE-26Nov18-v1.0.pdf

Hall. M. (2018), Norwegian Gas Exports: assessment of resources and supply to 2035, OIES Paper NG127.

Hanna, R. Gazis, E. Edge, J. Rhodes, A. and Gross, R. Unlocking the potential of Energy Systems Integration, Energy Futures Lab, Imperial College, April 2018. https://www.imperial.ac.uk/energyfutures-lab/policy/briefing-papers/paper-2/

Henderson, J. and Sharples, J. (2018): Gazprom in Europe - two "Anni Mirabiles", but can it continue? OIES Energy Insight: 29.

Hennig, E. 'The role of distribution infrastructure', presentation to the Madrid Forum, October 16, 2018.

Honoré, A. (2018): Natural Gas Demand in Europe in 2017 and short term expectations, OIES Energy Insight: 35. 

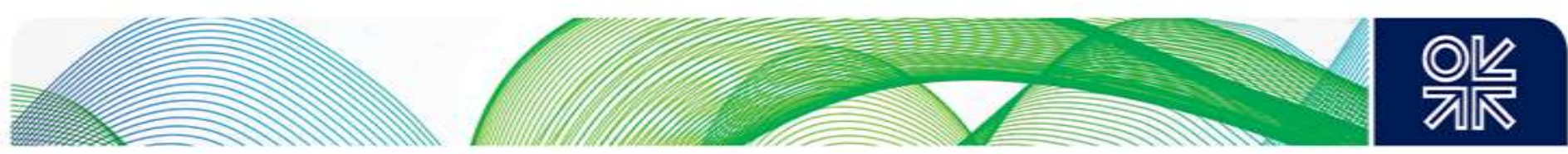

Honoré, A. (2017): The Dutch Gas Market: trials, tribulations and trends, OIES Paper NG 118.

IEA (2018): World Energy Outlook 2018. Paris: OECD.

IEA (2017): World Energy Outlook 2017. Paris: OECD.

IOGP (2018): CCS Projects in Europe, October 2018. https://32zn56499nov99m251h4e9t8wpengine.netdna-ssl.com/wp-content/uploads/2018/09/Map-of-EU-CCS-Projects10.pdf

Institute for Sustainable Process Technology, Power to Ammonia: feasibility study for the value chains and business cases to produce $\mathrm{CO}_{2}$-free ammonia suitable for various market applications.

http://www.ispt.eu/media/ISPT-P2A-Final-Report.pdf

Karlsruhr Institute of Technology (2018): 'Crack it! Energy from a Fossil Fuel without carbon dioxide', Press Release 139/2015. https://www.kit.edu/kit/english/pi 2015139 crack-it-energy-from-a-fossilfuel-without-carbon-di-oxide.php

Keay, M. (2018). Decarbonisation of heat and the role of 'green gas' in the United Kingdom, OIES Paper EL 29.

Lambert, M. (2017). Biogas: a significant contribution to decarbonising gas markets? Oxford Energy Insight 15.

Lambert, M. (2018a). Power-to-Gas: linking electricity and gas in a decarbonising world? Oxford Energy Insight 39.

Lambert, M. (2018b): 'Biogas, Biomethane and Power to Gas', Oxford Energy Forum, Issue 116, pp.3-7.

Leeds City Gate H21 (2016): https://www.northerngasnetworks.co.uk/wpcontent/uploads/2017/04/H21-Report-Interactive-PDF-July-2016.compressed.pdf

Le Fevre, C. (2017): Methane Emissions: from blind spot to spotlight, OIES Paper 122. https://www.oxfordenergy.org/publications/methane-emissions-blind-spot-spotlight/

Lincke, G. 'DGVW on effective emission reduction in the power, heat and transport sector', presentation to the Madrid Forum, October 16-17, 2018.

Lohmann, H. (2018), 'Topic of the Month: Hydrogen', Energate, May 2018, pp.32-38.

Lopez-Nicholas, A. 'Renewable Gas in the Revised Renewable Energy Directive post 2020', presentation to the Madrid Forum, October 16-17, 2018.

Madrid Forum 2018: all presentations and background documents can be found at https://ec.europa.eu/energy/en/events/madrid-forum

McGlade, C., Pye, S., Ekins, P., Bradshaw, M. and Watson, J. 'The future role of natural gas in the UK: a bridge to nowhere', Energy Policy, Vo. 113, 2018, pp. 454-465.

Nagashima, M. Japan's hydrogen strategy and its economic and geopolitical implications, IFRI, October 2018. https://www.ifri.org/en/publications/etudes-de-lifri/japans-hydrogen-strategy-and-itseconomic-and-geopolitical-implications

Oilchange International (2017), 'Burning the Gas 'Bridge Fuel' Myth', 9 November 2017, http://priceofoil.org/2017/11/09/burning-the-gas-bridge-fuel-myth/.

Pirani, S. (2018a): Russian Gas Transit Through Ukraine After 2019: the options, OIES Energy Insight: 41.

Pirani, S. (2018b): Let's Not Exaggerate: Southern Gas Corridor Prospects to 2030, OIES Paper NG 135. 

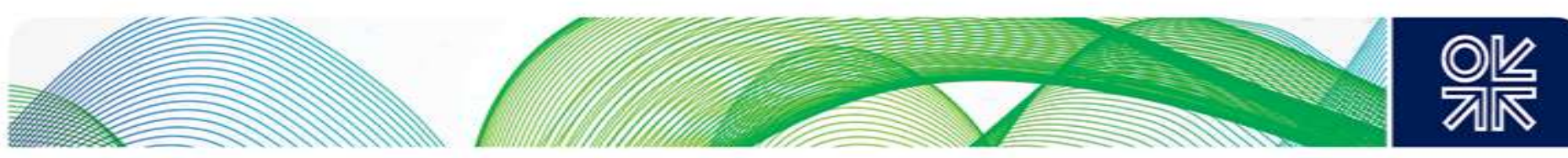

Pöyry (2018): 'Fully Decarbonising Europe's Energy System by 2050', May 2018. http://www.poyry.com/news/articles/fully-decarbonising-europes-energy-system-2050

Rogers, H. (2017): Does the Portfolio Business Model Spell the End of Long-Term Oil-Indexed Contracts? OIES Energy Insight: 10.

Shell Scenarios, Sky: Meeting the Goals of the Paris Agreement. https://www.shell.com/energy-andinnovation/the-energy-future/scenarios/shell-scenario-sky.html

Smyth, J. 'Chevron under fire over delayed Australian carbon capture plan', Financial Times, June 16/17, 2018.

Stern, J. and Yafimava, K. (2017): The EU Competition Investigation into Gazprom Sales to Central and Eastern Europe: a detailed analysis of the commitments and the way forward, OIES Paper NG 121.

Stern, J. (2017a): The Future of Gas in Decarbonising European Energy Markets: the need for a new approach, OIES Paper NG 116.

Stern, J. (2017b): Challenges to the Future of Gas: unburnable or unaffordable? OIES paper 125.

Yafimava, K. (2018): Building New Gas Transmission Infrastructure in the EU: what are the rules of the game? OIES Paper NG 134.

Yafimava, K. (2017a): The Council Legal Service's Assessment of the European Commission's Negotiating Mandate and what it means for Nord Stream 2, OIES Energy Insight: 19.

Yafimava, K. (2017b): The OPAL Exemption Decision: a comment on the CJEU's decision to reject suspension, OIES Energy Insight: 18.

Zero Emissions Platform, 'Commercial Scale Feasibility of Clean Hydrogen', April 2017. http://www.zeroemissionsplatform.eu/extranet-library/publication/272-cleanhydrogen.html 